Florida International University

FIU Digital Commons

FIU Electronic Theses and Dissertations

University Graduate School

7-22-1993

\title{
A model of the hydrothermal system at Casa Diablo in Long Valley, California, based on resistivity profiles and soil mercury analyses
}

John David Arfstrom

Florida International University

DOI: $10.25148 /$ etd.FI14032338

Follow this and additional works at: https://digitalcommons.fiu.edu/etd

Part of the Geology Commons

\section{Recommended Citation}

Arfstrom, John David, "A model of the hydrothermal system at Casa Diablo in Long Valley, California, based on resistivity profiles and soil mercury analyses" (1993). FIU Electronic Theses and Dissertations. 1306.

https://digitalcommons.fiu.edu/etd/1306

This work is brought to you for free and open access by the University Graduate School at FIU Digital Commons. It has been accepted for inclusion in FIU Electronic Theses and Dissertations by an authorized administrator of FIU Digital Commons. For more information, please contact dcc@fiu.edu. 


\title{
ABSTRACT OF THE THESIS
}

\begin{abstract}
A Model of the Hydrothermal System at Casa Diablo in Long Valley, California, based on Resistivity Profiles and Soil Mercury Analyses.
\end{abstract}

b y

\author{
John David Arfstrom \\ Florida International University, 1993 \\ Miami, Florida \\ Dr. Andrew Macfarlane, Major Professor
}

A description and model of the near-surface hydrothermal system at Casa Diablo, with its implications for the larger-scale hydrothermal system of Long Valley, California, is presented. The data include resistivity profiles with pentetrations to three different depth ranges, and analyses of inorganic mercury concentrations in 144 soil samples taken over a 1.3 by $1.7 \mathrm{~km}$ area. Analyses of the data together with the mapping of active surface hydrothermal features (fumaroles, mudpots, etc.), has revealed that the relationship between the hydrothermal system, surface hydrothermal activity, and mercury anomalies is strongly controlled by faults and topography. There are, however, more subtle factors 
responsible for the location of many active and anomalous zones such as fractures, zones of high permeability, and interactions between hydrothermal and cooler groundwater. In addition, the near-surface location of the upwelling from the deep hydrothermal reservoir, which supplies the geothermal power plants at Casa Diablo and the numerous hot pools in the caldera with hydrothermal water, has been detected. The data indicate that after upwelling the hydrothermal water flows eastward at shallow depth for at least 2 $\mathrm{km}$ and probably continues another $10 \mathrm{~km}$ to the east, all the way to Lake Crowley. 


\title{
FLORIDA INTERNATIONAL UNIVERSITY \\ Miami, Florida
}

\begin{abstract}
A Model of the Hydrothermal System
at Casa Diablo in Long Valley, California, based on Resistivity Profiles and Soil Mercury Analyses.
\end{abstract}

A thesis submitted in partial satisfaction of the requirements for the degree of Masters of Science in Geology

by

John David Arfstrom 
To Professors Andrew Macfarlane, Grenville Draper, and Bradford Clement:

This thesis, having been approved in respect to form and mechanical execution, is referred to you for judgement upon its substantial merit.

Dean Arthur W. Herriot

College of Arts and Science

The thesis of John David Arfstrom is approved.

Date of Examination: 7/22/93
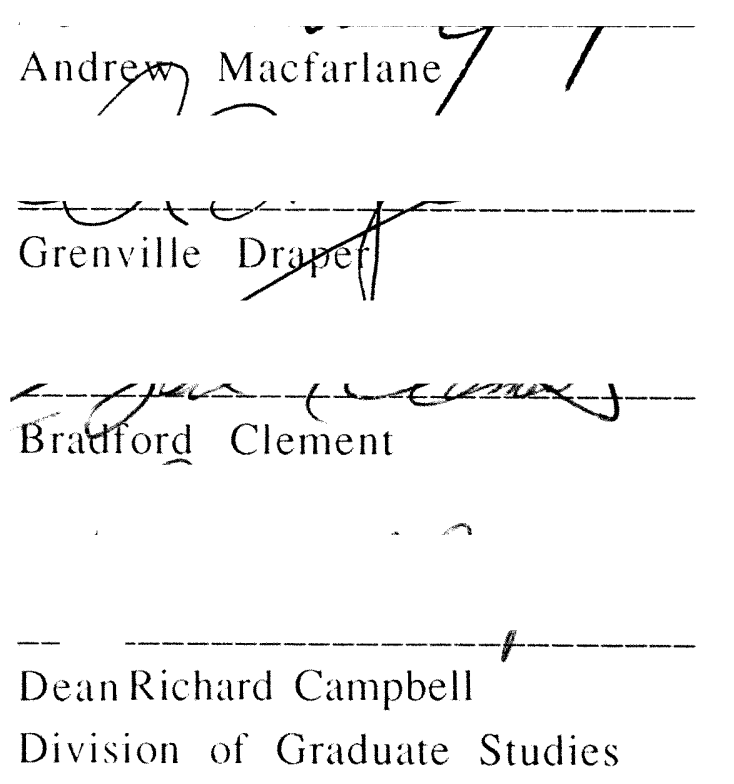

Florida International University, 1993 


\section{ACKNOWLEDGEMENTS}

Very special thanks goes to Cleone Arfstrom. Her tireless effort during the strenuous field-work phase of this study was both impressive and invaluable. Without her help, only a fraction of the data used in this study would have been collected. I will be eternally grateful for her assistance.

I would like to give thanks to Jim Anderson of Mammoth Pacific for providing access to the power plant property. His assistance is appreciated. Thanks goes to Jennifer Thomas for her mercury analyses of the soil samples. The help and advice of the geology professors at Florida International University, especially Chuck Connor (who conceived and arranged funding for this project), Andrew Macfarlane, Grenville Draper, Bradford Clement, David Genereux, and Rosemary Hickey-Vargas, is appreciated. 


\section{TABLEOFCONTENTS}

PAGE

ABSTRACT

ACKNOWLEDGEMENTS ...............................................................

LIST OF FIGURES ....................................................................

LIST OF TABLES ......................................................................... vi

CHAPTER 1: INTRODUCTION ...................................................... 1

STATEMENT OF PURPOSE ................................................ 1

REGIONAL SETTING AND HISTORY ................................ 2

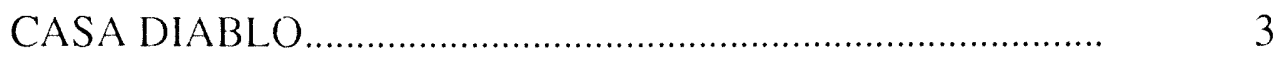

THE POWER PLANTS ........................................................ 6

CHAPTER 2: RESISTIVITY STUDIES AT CASA DIABLO........ I 3

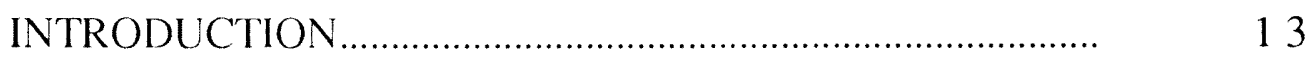

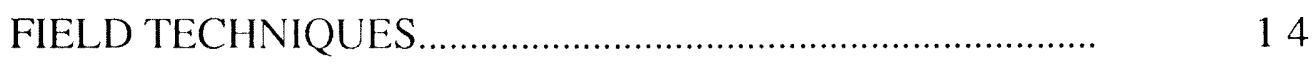

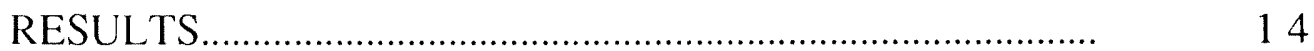

DISCUSSION OF RESISTIVITY DATA ............................ 16

CHAPTER 3: MERCURY ANALYSIS............................................. 36

INTRODUCTION ............................................................ $\quad 36$

FIELD TECHNIQUES........................................................ $\quad 36$

LABORATORY TECHNIQUES............................................... 37

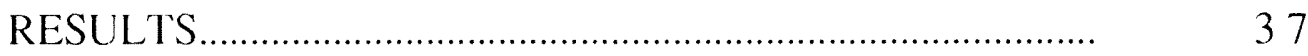

DISCUSSION OF MERCURY ANAL YSES............................ 40

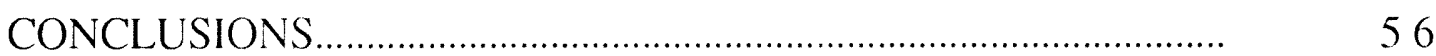

FURTHER WORK

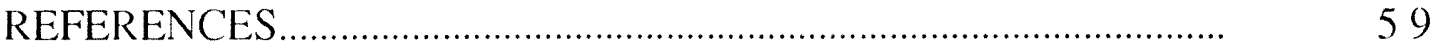




\section{LIST OF FIGURES}

PAGE

FIGURE 1.1. Location of Long Valley and Casa Diablo........... 8

FIGURE 1.2. Direction of groundwater flow.......................... 9

FIGURE 1.3. Map of study areat................................................. 10

FIGURE 1.4. Pressure-depth relation of geothermal system. 11

FIGURE 1.5. Temperature depth profile of well M-1........... 12

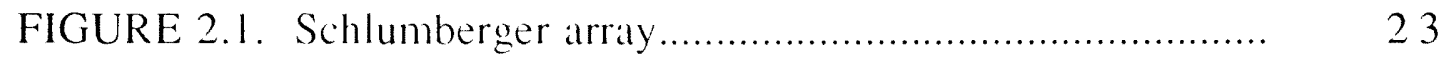

FIGURE 2.2. Contour map of 20m L-spacing......................... 24

FIGURE 2.3. Contour map of $5(\mathrm{~m}$ L-spacing........................... 25

FIGURE 2.4. Contour map of 1()() $\mathrm{m} \mathrm{L}$-spacing....................... 26

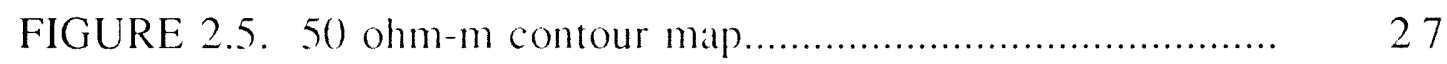

FIGURE 2.6. Contour map of depth to 50 ohm-m................. 28

FIGURE 2.7. Surfer generated contour map........................... 29

FIGURE 2.8. Surface of the hydrothermal system................. 30

FIGURE 2.9. The hydrothermal system with elevation........ 31

FIGURE 2.10. Temperature-depth profile of well M-1....... 32 
FIGURE 2.11. Temperature-depth profiles of wells 44-16, RDO-8, and PLV-1

FIGURE 2.12. Map showing location of wells and section.....

FIGURE 2.13. Hydrologic section................................................... 35

FIGURE 3.1. Map of soil mercury samples................................ 36

FIGURE 3.2. Log probability plot of total data set................... 37

FIGURE 3.3. Log probability plot of separated data set........ 38

FIGURE 3.4. Contour map of mercury concentrations............. 40

FIGURE 3.5. Distribution of soil types............................................ 41

FIGURE 3.6. Mercury concentrations across faults................. 42

FIGURE 3.7. 1975 and 1982 mercury anomalies..................... 43

FIGURE 3.8. Mercury anomalies at Casal Diablo........................ 44

FIGURE 3.9. 50 ohm-m contour and mercury anomalies.... 45 


\section{LIST OF TABLES}

PAGE

TABLE 3.1. Probability distribution of mercury................... 39

TABLE 3.2. Precipitation at Lake Mary...................................... 46 


\section{CHAPTER 1: INTRODUCTION}

\section{STATEMENT OF PURPOSE}

The first primary goal of this study is to understand why surface hydrothermal features are so abundant at Casa Diablo. There are several locations of surface hydrothermal activity throughout Long Valley with Casa Diablo being the most active. This surface activity is fed by a hydrothermal system of considerable spatial extent, and yet surface activity throughout the Long Valley is limited to discrete zones. This study examines this question in the Casa Diablo area, and provides insight into what is happening at the other sites of surface activity.

The second primary goal is to understand what determines the exact placement of surface hydrothermal features at Casa Diablo. Surface hydrothermal features in the Casa Diablo area are themselves very discretely distributed. Explaining the location of individual surface hydrothermal features requires a detailed investigation of the location and movement of the hydrothermal system. Although many previous studies have dealt with this problem in general way, very few have treated it in the detail of this study. Only detailed investigations, with a high density of data, can hope to solve this problem.

A secondary goal of this thesis is to test the effectiveness of the joint use of resistivity profiling and soil mercury analyses applied to hydrothermal systems. Each technique provides its own particular insights, but together reveal more than they could individually. Resistivity profiling can reveal the depth to hydrothermally permeated rocks by means of the commonly high ion content of hydrothermal water, which lowers electrical resistance of rock. Adding to this, mercury analyses can indicate locations of mercury enrichment caused by vaporization, which suggests an upward flow of hydrothermal water. This information is basic and vital to any study of the near surface behavior of hydrothermal systems. 
The Long Valley caldera is located in east-central California, about $40 \mathrm{~km}$ south of Mono Lake (Fig. 1.1). The dimensions of the caldera floor are 17 by $30 \mathrm{~km}$, with its long axis aligned east-west. Cenozoic volcanic activity in the area began about $3.2 \mathrm{~m} . \mathrm{y}$. ago. The calderaforming eruption occurred around 0.7 m.y. ago. A resurgent dome about $10 \mathrm{~km}$ in diameter formed by $0.6 \mathrm{~m}$.y. ago, slightly to the west of the center of the caldera (Fig. 1.2). The most recent eruption formed a cinder cone in the northwestern part of the caldera as recently as 450 years ago (Bailey et al., 1976). Previous geophysical investigations including seismic activity, indicate the presence of magma at depths of $6-8 \mathrm{~km}$ (Hill, 1970), and analysis of earthquake hypocenter distributions suggest a high-temperature ductile zone as shallow as $4 \mathrm{~km}$ under the western part of the caldera between the resurgent dome and the west rim (Hill, 1989). The magma is believed to be the heat source which drives the hydrothermal system of the caldera. It has been estimated that this system is potentially one of the best for electric power development in the western United States (Nathenson and Muffler, 1975).

The source reservoir is believed to exist in metamorphic basement rock at a depth of 2 to $4 \mathrm{~km}$, as indicated by resistivity interpretations, temperature profiles, and geochemical evidence. Structural features associated with several stratigraphic displacements revealed by drilling may control the movement of hydrothermal water into and out of the source reservoir. However, its depth, location, and extent are not known (Sorey et al., 1991).

The flow paths of hydrothermal water and the location of hot springs, fumaroles, and mudpots throughout the caldera is influenced by recurring and widespread movement along faults that concentrate the hydrothermal flow. Well data indicates upward flow from a deep $(2-4 \mathrm{~km})$ source reservoir under the western part of the caldera, followed by lateral flow at very shallow depths $(<200 \mathrm{~m})$ generally towards the east (Fig. 1.2). It passes under the Casa Diablo and continues until it discharges into Lake Crowley (Sorey et al., 1991). 
Temperature profiles and chemical analyses of well waters demonstrate that the temperature of the hydrothermal water decreases gradually as it flows eastward due to mixing with cooler ground water. Temperatures in the source reservoir are estimated to be between 214 and $240{ }^{\circ} \mathrm{C}$ from drill-hole measurements and chemical geothermometry, although no direct measurement has been made (Sorey et al.,1991). At Casa Diablo (Fig. 1.3) the peak temperature measured was $172{ }^{\circ} \mathrm{C}$ about $100 \mathrm{~m}$ below the surface in an exploratory well (M-1) supervised by T.C. Urban, U.S. Geological Survey. Peak temperature was measured at only $50 \mathrm{C}$ near Lake Crowley at a depth of $25 \mathrm{~m}$ in well CH-3 (Sorey, 1985).

Surface temperatures of thermal features measured throughout the caldera are lower than peak temperatures measured at depth in wells. Temperature decreases gradually toward the surface due to mixing with infiltrating meteoric water, expansion and vaporization as water rises to lower pressures, and conductive heat loss through the ground. At Casa Diablo, surface temperatures of thermal features are near the boiling point, which is $93^{\circ} \mathrm{C}$ at the local elevation of $2230 \mathrm{~m}$ or $7,300 \mathrm{ft}$.

\section{CASA DIABLO}

Spanish for "House of the Devil", Casa Diablo was so named long before the area became the site of the present day power plants, the development of which began in the 1960's. Casa Diablo has been an area natural thermal discharge for as long as the regions recorded history, with several periods of active geyser formation (Farrar et al., 1989). Hydrothermal activity has historically been cyclic but unpredictable. Zones of surface hydrothermal activity have migrated, gone extinct, and become active again over the decades. Activity at present is characterized by very little runoff with the majority of rising hydrothermal fluid escaping to the atmosphere as vapor. Some have speculated that the "dry" nature of the activity may result from some effect of the power plants on the delicate balance between the hydrothermal fluid and subsurface features. 
However, the natural instability of the system makes this difficult to prove.

The hydrothermal system at Casa Diablo is water dominated, as opposed to vapor dominated. This is indicated by well logs which show that hydrothermal water is within meters of the surface, and by the large volume of hydrothermal water that is continuously pumped from a depth of $150 \mathrm{~m}$ for electrical generation. Small vapor-dominated zones may exist beneath the larger and more vigorous fumaroles, but mudpots and bubbling pools that produce runoff are always present nearby. The hydrothermal fluids beneath zones of surface activity are probably mixtures of both water and vapor.

Henley (1985) described the conditions that lead to two-phase flow (water and vapor) beneath surface hydrothermal features in water dominated systems. When hydrothermal water flows upward through a high permeability conduit, the resulting decrease in pressure causes a phase separation (Figure 1.4). The rising hydrothermal water essentially boils until its temperature drops to the point where it is in equilibrium with the pressure it is experiencing. If it continues to rise, it will continue to boil until it reaches the surface, at which point its temperature will be equal to the boiling point at the local elevation.

This is exactly what occurs at Casa Diablo. The boiling point at Casa Diablo is $93^{\circ} \mathrm{C}$, and the surface hydrothermal features are consistently within I degree of this temperature. Figure 1.5 shows the temperature versus depth profile of Casa Diablo well M-1 superimposed on a phase diagram showing temperature versus depth curves of water of varying compositions. Although the comparison is not ideal, as a well cannot perfectly represent true subsurface conditions, it does demonstrate that subsurface boiling at Casa Diablo has maintained equilibrium or at least near equilibrium temperature versus depth conditions.

In terms of free versus forced convection, previous studies at Casa Diablo (Song, in preparation) and in the vicinity of Casa Diablo (Farrar, 1987), have concluded that the vapor flux from fumaroles is 
inversely related to atmospheric pressure. Forced convective systems are driven by pressure gradients, whereas free convective systems are driven by the buoyancy of the vapor. Therefore, the convection of hydrothermal fluid at Casa Diablo should be forced.

Most of the fumaroles at Casa Diablo probably depend on forced convection, because the clay formation and mineralization of the ground around them restricts flow. There are many patches of gently steaming ground, however, that may result from free convection. It is possible that near-surface groundwater, from rain and snow melt, is heated from below by rising vapor. When the boiling point is reached in these patches, they will gently boil. The vapor may then rise to the surface by free convection if the ground has not yet become impermeable.

The numerous surface hydrothermal features at Casa Diablo range from vigorous fumaroles and large mudpots that are several meters in diameter, to small, gently bubbling pools and steaming ground. Patches of dying trees are very common in the area. Close inspection of these patches nearly always reveals small fumaroles, steaming ground, or at least abnormally warm soil a few centimeters below the surface. Because of their large numbers and spatial extent, the only practical way to map the surface hydrothermal features at Casa Diablo is by zones. The enclosed shaded areas on Figure 1.3, which were mapped during the field-work phase of this study, represent these zones in which any form of surface hydrothermal activity is present.

The exposed rocks at Casa Diablo are rhyolitic lavas and felsic tuffs that are extensively altered to clatys at sites of past and present hydrothermal surface activity. This alteration plays an important role in the evolution of surface activity; clays, together with precipitation of silica and other minerals, may seal up the zones of high permeability, eventually causing many zones of activity to become extinct (Henley, 1985). Seismic activity may reopen existing fractures or open new ones, perhaps explaining the cyclic and migratory nature of the surface hydrothermal features. 
North of the power plants, the southernmost extension of the resurgent dome rises from the relatively flat topography that is characteristic of Long Valley. The tanks marked on the area map (Figure 1.3) are situated on top of a hill that marks the southern flank of the resurgent dome. The resurgent dome is covered by pine trees which appear to grow better there.

South of the tanks is a flat area that is covered by brush, grasses, and occasional. Covering parts of the flat area are several basalt flows that originate from an extinct vent to the west, near the city of Mammoth Lakes. The largest of these flows is no more than a few tens of meters wide and a few meters thick, and are of no consequence to the hydrothermal system at Casa Diablo. All of the basalt flows are located to the south of the power plants and old Highway 395.

The most important structural features within the study area are two NNW-SSE trending normal faults and the graben between them (Figure 1.3). Both faults almost certainly penetrate down into the hydrothermal system since most of the surface activity at Casa Diablo is concentrated along the two faults.

\section{THE POWER PLANTS}

The three power plants at Casa Diablo are run by Mammoth Pacific and have a combined output of 25 megawatts. Hydrothermal water at a temperature of about $170{ }^{\circ} \mathrm{C}$ is drawn up through as many as 13 production wells from at depth of $150 \mathrm{~m}$ and, after passing through heat exchangers in which it is cooled somewhat, is injected back into the ground to a depth of $70(1) \mathrm{m}$ through as many as 7 injection wells.

The power plants are unique in that they incorporate a double closed loop design which eliminates the need for hydrothermal water to enter the turbines and the necessary vaporization of the water. The advantage is that the usual scaling of minerals on the insides of the turbines which is accelerated by boiling, and the expensive maintenance associated with it, is eliminated. Instead, when the 
hydrothermal water is passed through the heat exchangers, isobutane is heated to $150^{\circ} \mathrm{C}$ (in a separate loop), which then vaporizes and is used to drive the turbines. The isobutane is then cooled and liquified by fan powered condensers and sent back to the heat exchangers to repeat the cycle in a closed loop.

Similarly, the hydrothermal water is restricted to a closed loop in the sense that it is not released at the surface. Although in reality the hydrothermal fluid is injected to a greater depth than from which it is taken and very little of it finds its way back to the production wells. Indeed, this would not be desirable as it would cool the hydrothermal water drawn from the production wells. In fairness, the only way to create a true closed loop system at Casa Diablo would be to inject spent hydrothermal water several kilometers down to where it was initially generated, as with dry geothermal systems. This would not be financially practical, not to mention the fact that the location of the source is not exactly known.

On the positive side, the injection may help to maintain the hydraulic head which may in turn help to prevent a drop of the water table, which could be undesirable for the power plant and adjacent areas. A more definite advantage of the injection is that the hydrothermal water, with its high levels of dissolved metals, is not discharged at the surface where it can do harm. 


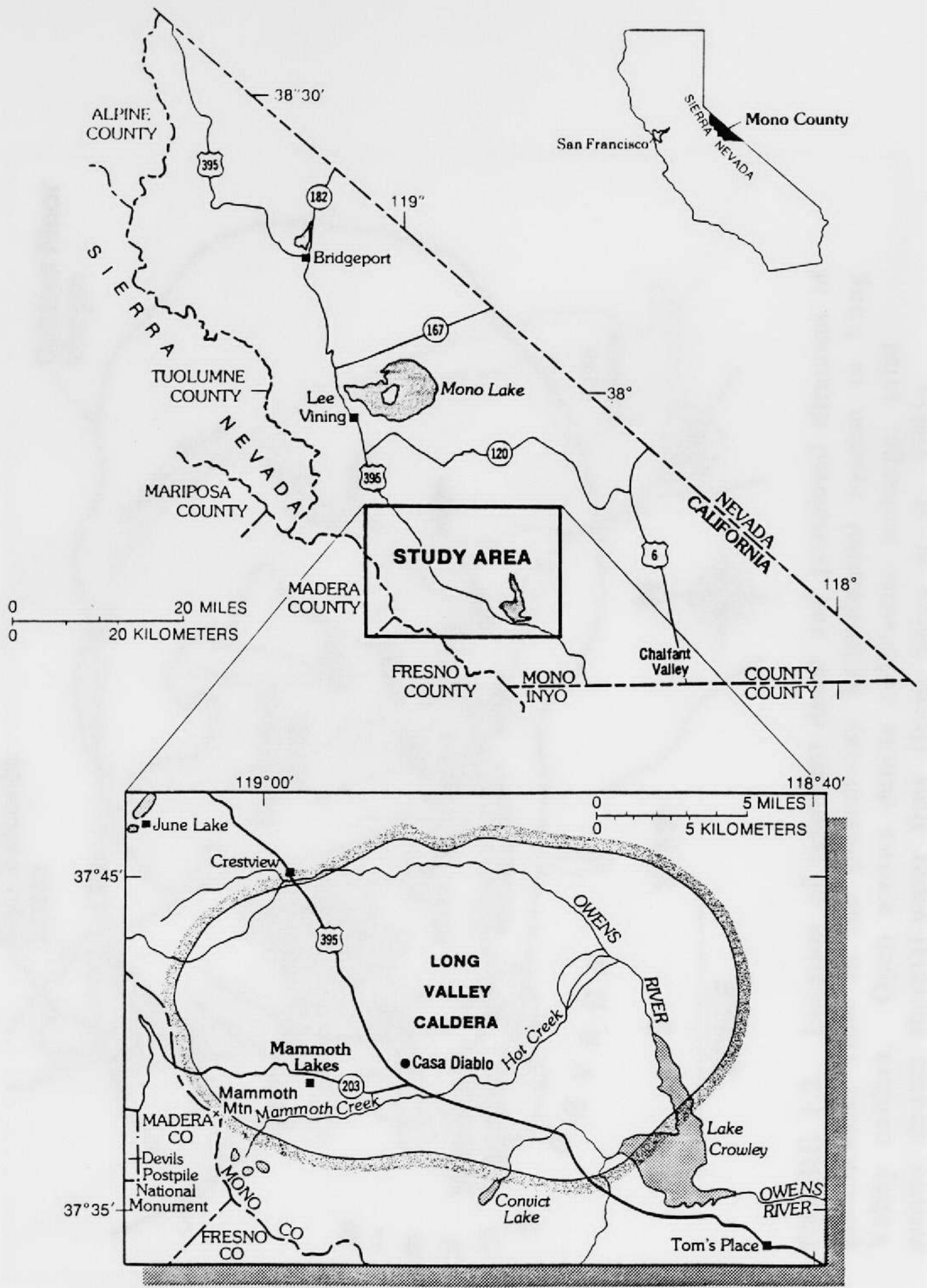

FIGURE 1.1. Location of Long Valley and Casa Diablo (modified from Farrar et al., 1986). 


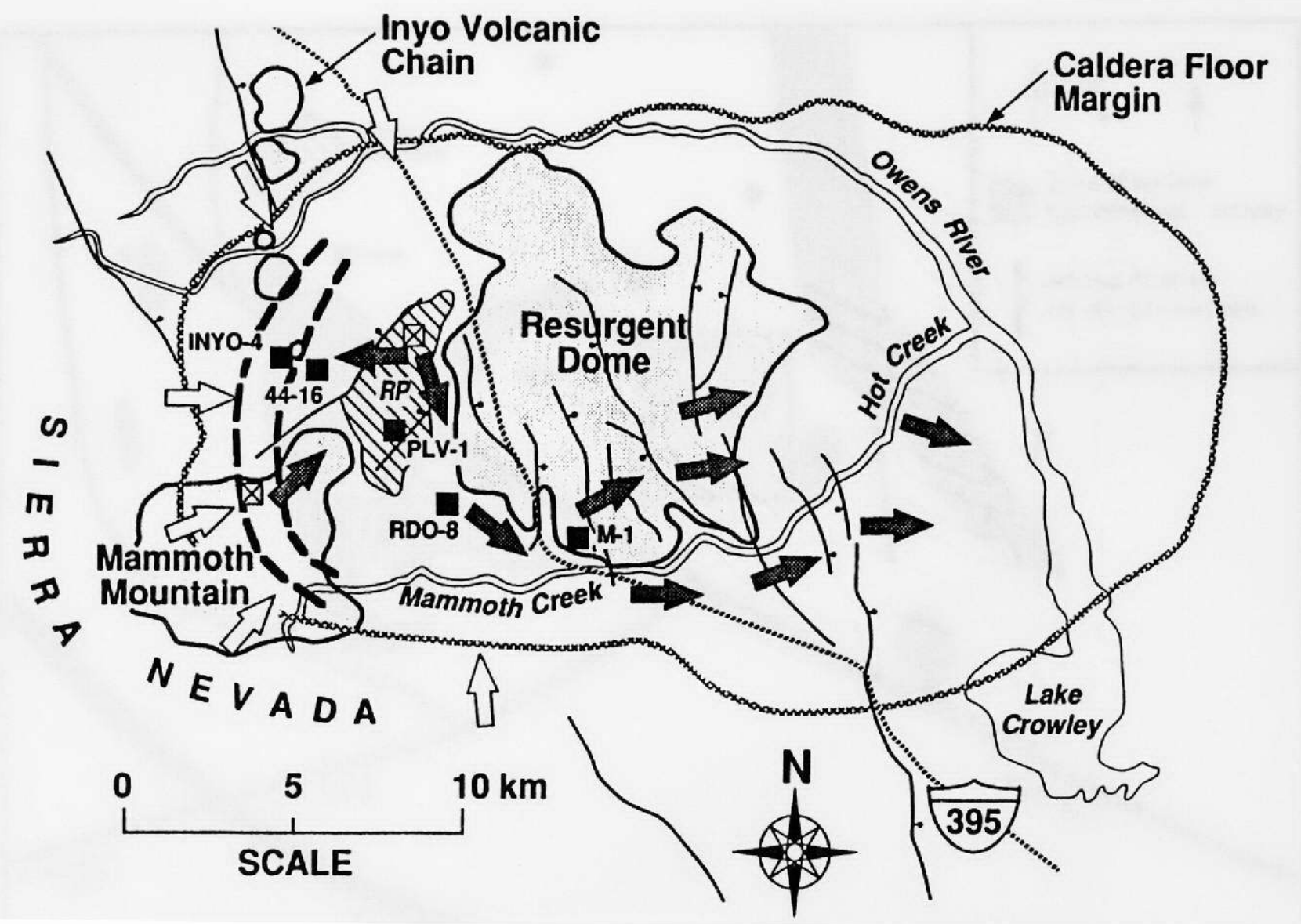

FIGURE 1.2. Location of resurgent dome and postulated direction of groundwater flow in the present-day hydrothermal system in Long Valley caldera. Open arrows denote cold-water recharge; solid arrows denote thermal-water flow (from Sorey et al., 1991). 


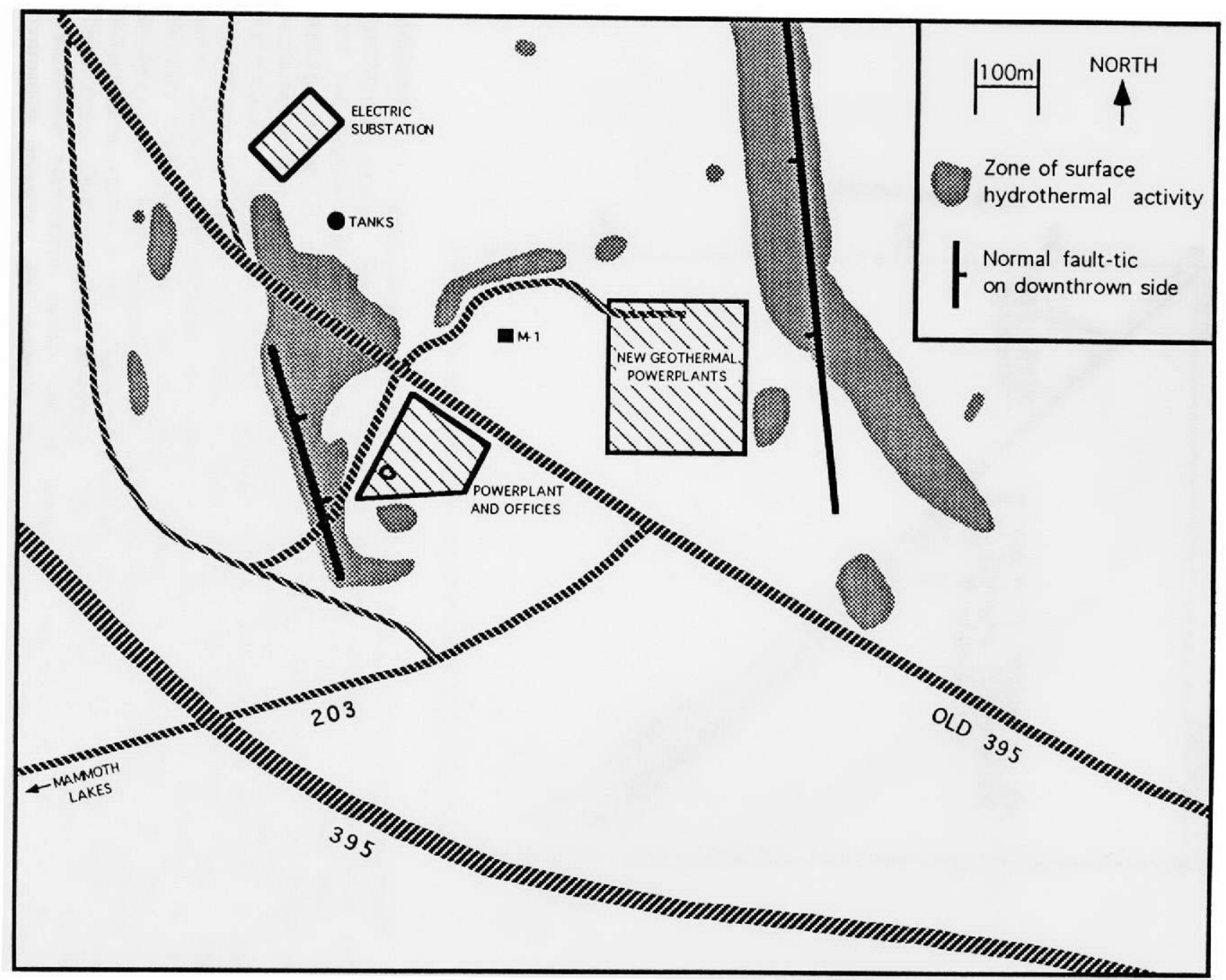

FIGURE 1.3. Map of study area showing location of well M-1. 


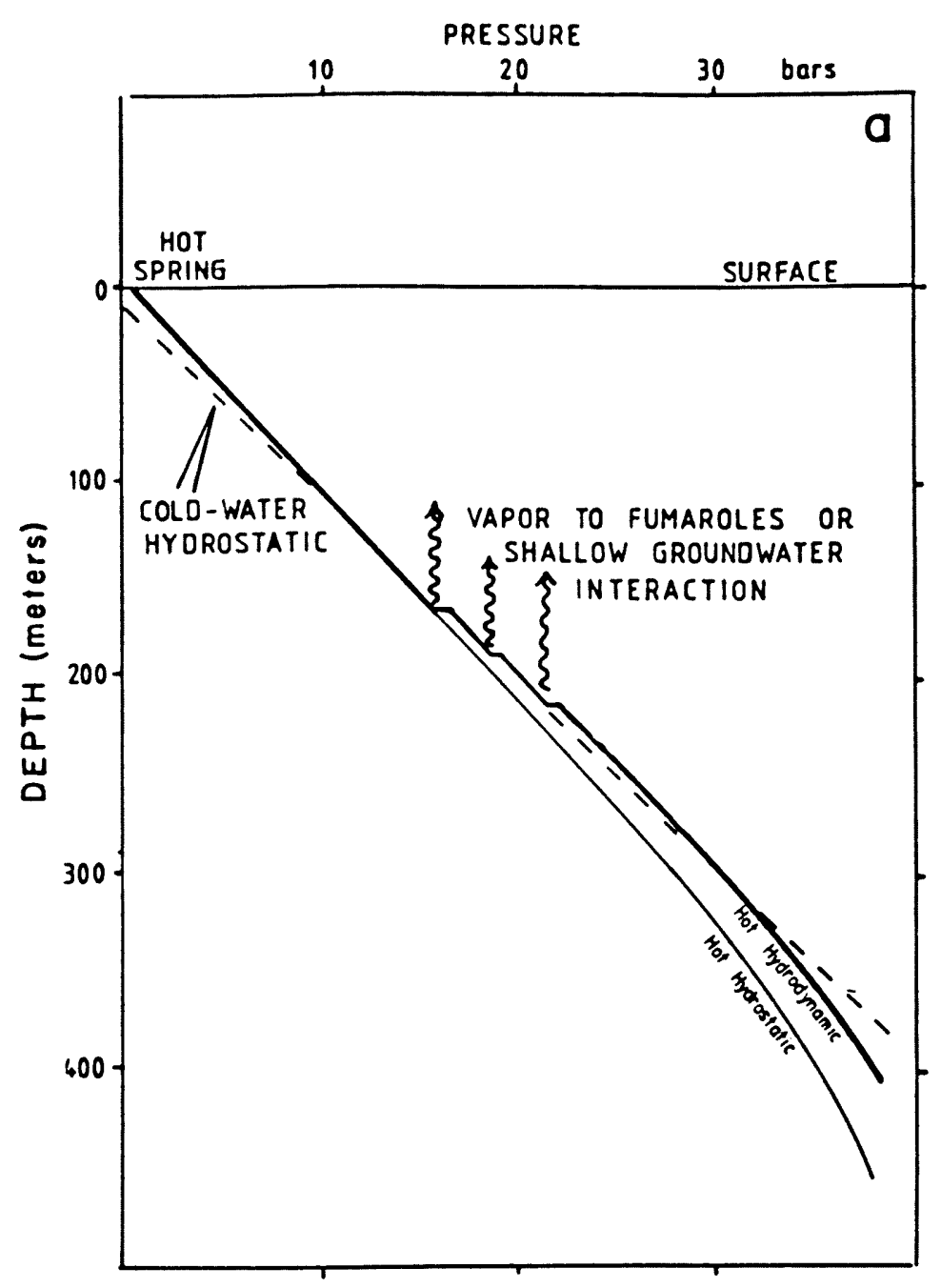

FIGURE 1.4. Pressure-depth relations in the upper portion of a water dominated geothermal system. The diagram shows the transition between the deep system pressure and the pressure within the high permeability fracture network or conduit below a hot spring. Below the hot spring, the pressure at a specific depth is due to the weight of a standing column of hot water; the pressure-depth relation is here designated "hot hydrostatic". Deeper in a system, pressure exceeds hydrostatic so that flow is maintained through the permeable aquifer--this is shown as the "hot hydrodynamic" curve. Some minor pressure discontinuities are shown to indicate the possible occurrence of minor throttles which may occur due to fracture geometry or mineralization, but these are probably rare. Phase separation may occur resulting in the presence of fumaroles or steam-heated waters in the vicinity of a boiling hot spring (e.g., Norris Geyser Basin, Yellowstone, Chamagne Pool, Waiotapu). The effect of raising or lowering the ambient groundwater piezometric surface may be gauged by redrawing the curve for cold-water hydrostatic pressure. For example, if the cold-water piezometric surface is at +20 meters and the hot-spring conduit is not isolated by mineral deposition, dilution may occur near surface. Dilution occurs on the margin of a hydrothermal system due to the relative pressure of cold groundwater over that of the hot-water system (from Henley, 1985). 


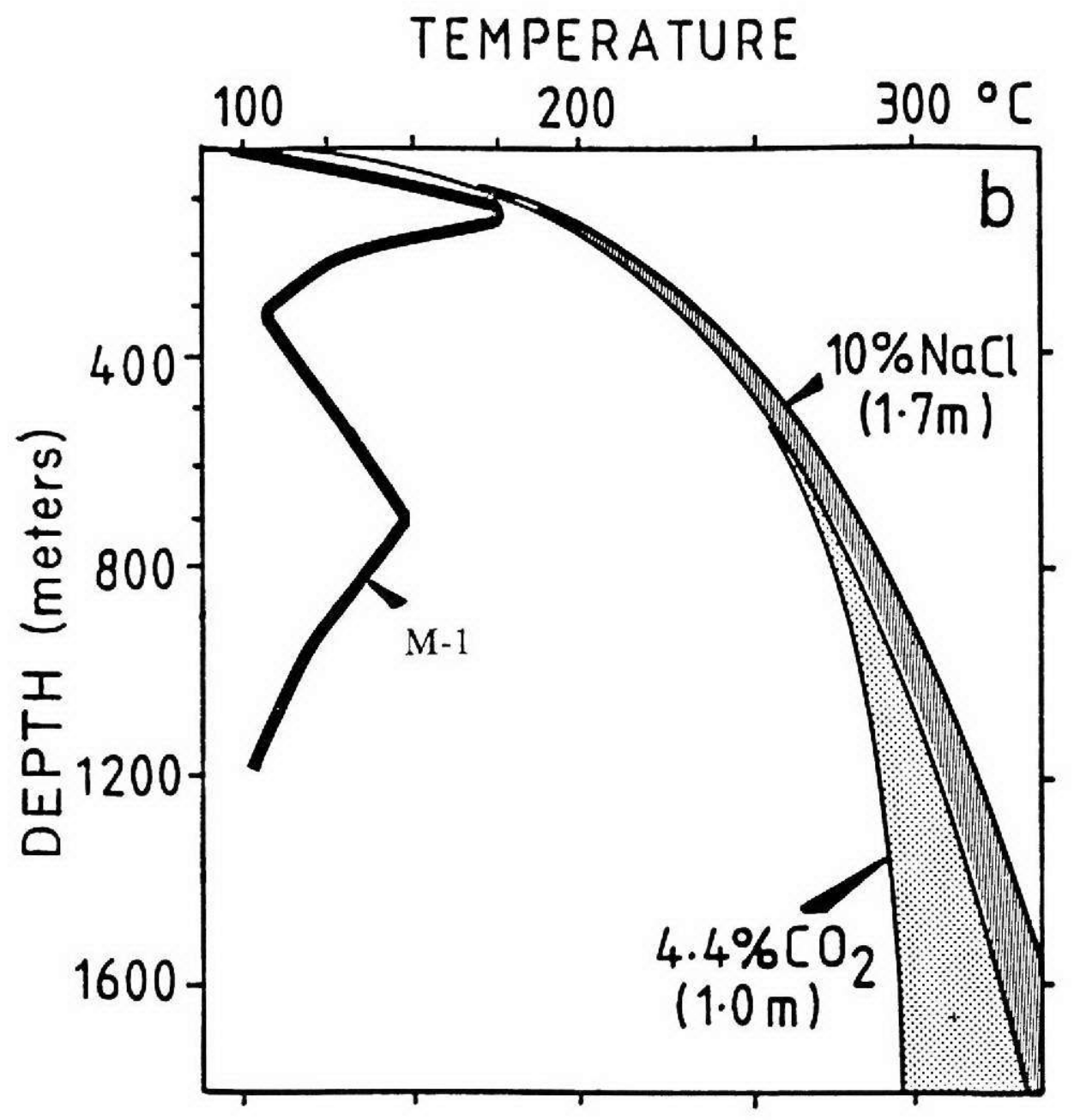

FIGURE 1.5. Temperature-depth profile of well M-1 (from Sorey et al., 1991) superimposed on the hydrostatic boiling-point versus depth relations of hydrothermal fluids with contrasting salinity and gas contents (from Henley, 1985). Observations of active systems suggest that pressure gradients at depth are about $10 \%$ greater than hydrostatic, allowing higher temperatures at shallower depth than shown here (Henley, 1985) 


\section{CHAPTER 2: RESISTIVITY STUDIES AT CASA DIABLO}

\section{INTRODUCTION}

Resistivity profiling is an ideal method of investigating why Casa Diablo is so hydrothermally active as compared to surrounding areas, and what controls the exact locations of surface hydrothermal features such as fumaroles and mudpots. This is because of the high conductivity of the hydrothermal water at Casa Diablo, due to its high ion content. Rock that is dry, or permeated with dilute cold groundwater, has a lower conductivity (higher resistance) than rock that is permeated with hydrothermal water of high ion content. Therefore, rocks that are permeated by hydrothermal water will show up as anomalous resistivity lows. Resistivity profiling can reveal the location and shape of the hydrothermal system through variations in the electrical resistance of the ground.

Henley (1985) discusses applications of the above principle to delineate the extent of hydrothermal water in the upper 500 meters of several geothermal areas. It was found that maximum resistivity gradients located by resistivity surveys reflected the contrast between unmineralized groundwater and the chloride rich water present in geothermal systems. The extent of low resistivities within the resistivity gradients indicated the extent of the areas where hydrothermal water was present.

A second valuable source of information concerning the location and shape of the hydrothermal system are temperature logs of wells that penetrate the hydrothermal system and the surrounding areas. Although many well logs of interest are proprietary, accessible data can prove useful. Temperature versus depth profiles of wells will demonstrate whether or not the hydrothermal system is present, and, if so, at what depth. Together, resistivity profiling and well logs can provide a good model of the location and shape of the hydrothermal system at. Casa Diablo. When the model is compared to a map of topography, fatults, and surface hydrothermal features, the central problems of why Casa Diablo is so hydrothermally active and 
what controls the locations of surface hydrothermal features should be answered.

\section{FIELD TECHNIQUES}

Resistivity data and soil samples were collected during a six week field trip through July and August of 1992. Research was a restricted to a 1.3 by $1.7 \mathrm{~km}$ area centered roughly on the power plants at Casa Diablo (Figure 1.3). The majority of the resistivity data and soil samples were collected along 13 separate east-west traverses which were bordered by Highway 395 to the southwest and by steep topography to the northeast. Much of the area surveyed fell within the property lines of the power plants which are run by Mammoth Pacific. Permission for access to the power plant property was attained prior to arriving at Casa Diablo. The remainder of the study area is mostly Forest Service land.

Resistivity measurements were taken with a Bison Instruments Earth Resistivity Meter (Model 2350) in the Schlumberger arrangement (Figure 2.1). Profiling was chosen over sounding because it permits a larger area to be covered in a given time. Data was collected using L-spacings of 20,50, and 1(1)( $) \mathrm{m}$. A total of 260 measurements were made at the L-spacing of $20 \mathrm{~m}, 120$ at the $\mathrm{L}$ spacing of $50 \mathrm{~m}$, and 26 at the L-spacing of $100 \mathrm{~m}$. An L-spacing of $100 \mathrm{~m}$ was the practical limit for the power and sensitivity of the Bison meter at this location.

\section{RESULTS}

During initial testing of the Bison resistivity meter at Casa Diablo it was determined that the maximum L-spacing that could be used was near 100 meters. The meter would not behave properly at greater L-spacings. Time restrictions limited the number of resistivity profile surveys at different L-spacings to three. A wide range of L-spacings was desirable at this would give information about resistivity at a wide range of depths. To satisfy this 
requirement, and the upper limit of $10(1) \mathrm{m}$, L-spacings of 20,50 and $100 \mathrm{~m}$ were chosen.

Figures 2.2, 2.3, and 2.4 are resistivity contour maps made from data collected from three surveys with L-spacings 20, 50, and $100 \mathrm{~m}$, respectively. The same $100 \mathrm{~m}$ grid was used to position measurement stations for all three surveys. Wherever measurement stations of the three surveys overlap, which was usually the case, the combination can be thought of as crude soundings. These resistivity contour maps reveal several things. First, an examination of Figure 2.2, which is the most shallow of the three maps, shows a good correlation of low resistivities (the $5($ ) ohm-m contour in particular) with surface activity (fumaroles, mudpots, steaming ground, and stands of dead trees) indicated by the shaded areas. This is especially true in the western half of the map area. Figure 2.3 shows the resistivity at 2.5 times the depth of Figure 2.2. The results are very similar to those of the shallower survey, but the 5() ohm-m contour line encloses more of the map area and is less closely associated with surface activity. Figure 2.4 indicates the resistivities at twice the depth of Figure 2.3 and shows the same trend. As before, the 50 ohm-m contour line encloses more of the map area and is even less correlated with surface activity. Figure 2.5 shows the 50 ohm-m contour lines of all three surveys plotted together, and helps to illustrate the pattern. More importantly, Figure 2.5 provides a three-dimensional view of resistivity and, indirectly, the hydrothermal system. This will be explained in the next section.

Besides the change in the overall pattern that is seen through the three successive resistivity contour maps, there are two other important features present in each. One is the strong resistivity gradient in the far western section of the map area (upwelling zone). The second is the continuation of low resistivities to the east (lateral flow). These features have important implications as to how the hydrothermal system at Casa Diablo relates to the hydrothermal system of Long Valley. 


\section{DISCUSSION OF RESISTIVITY DATA}

\section{Casa Diablo}

The good correlation of low resistivities with surface hydrothermal features, especially at the $20 \mathrm{~m}$ L-spacing (Figure 2.2), suggests that hydrothermal water in these zones is responsible for the low resistivities found there. This is reasonable because hydrothermal waters taken from wells in the area have ion concentrations of about 1,250 milligrams per liter of dissolved solids (Farrar et al., 1989), which is much higher than cold ground water concentrations. These low resistivities are most likely caused by rocks that are permeated with hydrothermal water and, in effect, delineate the upper part of the hydrothermal system (Henley, 1985).

The word "permeated" is used because the exact subsurface condition is unknown. For instance, the ground mat be saturated or unsaturated with hydrothermal fluid. Also, the relative percentage of hydrothermal water to vapor is unknown. Water versus vapor content is particularly important with respect to resistivity interpretations. Ground that is permeated with hydrothermal vapor and otherwise dry can demonstrate a high resistance. This is because hydrothermal vapor has a low ion concentration, and water vapor is not very conductive. No zones of high resistivity are apparent beneath the zones of surface hydrothermal activity in any of the three resistivity contour maps, and subsurface conditions at Casa Diablo make completely dry, vapor permeated zones unlikely (see Casa Diablo section, Chapter 1).

For the purpose of the following discussion, two assumptions must be made. First, it is assumed that zones of low resistivity are caused by and equivalent to hydrothermally permeated ground, regardless of the exact conditions. Secondly, ground that is sufficiently permeated by hydrothermal watter, ats lo caluse a low resistivity zone, is defined as a part of the hydrothermal system. Any method of defining the extent of a hydrothermal system is arbitrary since the transition from where it definitely exists to where it does not is 
gradual. Perhaps resistivity provides the best means of defining a border. The next step is to choose an apparent resistivity value that defines the border.

Ground that is saturated with hydrothermal fluid of high ion content can have resistivities of less than 10 ohm-m. However, the host ground of a hydrothermal system may not be uniformly or completely saturated. For instance, hydrothermal fluid could be concentrated in discrete patches, where permeability is high, causing resistance to be very low. Patches of less permeable ground may be relatively unaffected by the hydrothermal system and electrical resistance there may be much higher. A resistivity station that penetrates ground that is not uniformly permeated with hydrothermal fluid will average the resistance of individual patches. Therefore, ground that is permeated by a hydrothermal system may have an overall resistance greater than expected.

An apparent resistivity value of 5() $\mathrm{ohm}-\mathrm{m}$ is taken to indicate the border of the hydrothermal system at Casa Diablo. This is based on a comparison of the resistivities of the most shallow of the profiles $(20 \mathrm{~m}$ L-spacing) to the zones of surface hydrothermal activity. Apparent resistivity of $50 \mathrm{ohm-m}$ correlate well with near surface ground that is definitely permeated with hydrothermal fluid

In addition, instrument sensitivity and accuracy decreased as resistivities dropped below 50 ohm-m. Although the numerous uncertainties already discussed makes it clear that an exact choice of apparent resistivity is impossible, $50 \mathrm{ohm-m}$ is a reasonable approximation.

At an L-spacing of $50 \mathrm{~m}$ (Figure 2.3), the anomalies broaden when compared to the $20 \mathrm{~m}$ L-spacing, but still correlate well with the surface activity. The $10(0 \mathrm{~m}$ L-spacing (Figure 2.4) indicates that the majority of the area is underlain by a low resistivity zone. For a direct comparison, Figure 2.5 shows the $50 \mathrm{ohm-m}$ contour lines of all three L-spacings plotted together. I interpret this pattern to indicate that the hydrothermal system is broad at depth and tapers toward the surface beneath the zones of surface activity. One implication of this interpretation is that potentially productive areas 
could be mistakenly eliminated if the choice of drilling sites for geothermal production wells is based solely on surface activity. If the data of all three maps were combined it would be possible to construct a three dimensional surface of a given apparent resistivity value if each L-spacing is is given a depth designation. The actual depth a given L-spacing penetrates to varies depending on many factors. These include the effects of topography, which cannot be isolated in the case of anisotropic ground, and the depth, thickness, and geometry of soil and rock of contrasting resistivities, about which almost nothing is known. There is a range of depth, however, over which a given L-spacing most likely penetrates to. This is generally between 0.5 and 1 times the L-spacing. For example, a L-spacing of $20 \mathrm{~m}$ will give the resistivity at a depth between 10 and $20 \mathrm{~m}$. For the purpose of constructing the following models an approximate depth must be assigned to each L-spacing. The equation

$0.75(\mathrm{~L}-\mathrm{spacing})=$ depth

was chosen because 0.75 is the midpoint of the likely range. This gives apparent resistivity values at depths of 15,37 , and 75 meters for the 20, 50, and $100 \mathrm{~m} \mathrm{~L}$-spacings, respectively. It is stressed here that depths assigned in this manner are only approximate. An approximation of depth is acceptable for the following models because it is the proportionality of L-spacing to depth that is important. I assume this proportionality is constant for the three Lspacings. For purpose of this study, it is the overall pattern of resistivity that is of the greatest value. Approximations of depth do not seriously affect the resistivity patterns.

Figure 2.6 is a contour map of apparent resistivity of 50 ohm-m with contour lines at depths of 15,37 , and $75 \mathrm{~m}$. If it is assumed that an apparent resistivity of $50 \mathrm{ohm-m}$ is equivalent to the border between ground that is hydrothermally permeated enough to be considered a part of the hydrothermal system, and ground that is not, then Figure 2.6 shows the actual depth to the surface of the 
hydrothermally system. Although the exact value of 50 ohm-m is approximate, any value less than 100 ohm-m would give very similar results in this case. The main difference would be a minor broadening or narrowing of the general pattern. Because an exact apparent resistivity cannot be chosen with any real authority, it would be wise to think of Figure 2.6, and any model derived from it, as an approximation of the true depth to the hydrothermally system.

Zones of current surface activity might also indicate the depth to the hydrothermally system, which would seem to be equal to the surface itself. This may not be entirely true, as it is possible that one or more of these zones is caused by the boiling of near surface meteoric water that may have been heated, as some have postulated (Henley, 1985), by rising vapor from the true hydrothermally permeated zone at some greater depth. But, even active zones with origins such as this can be loosely thought of as a part of the hydrothermal system, and do indicate locations of upwelling and upward vapor flow. For the following model, active surface zones are considered to be a part of the hydrothermal system, and indicate a depth to it of zero.

Once all the datat was compiled, their positions were plotted on a horizontal ( $X$ and $Y$ ) grid, with depth data on a vertical axis (Z). The three dimensional data was then processed by a computer program called Surfer, which accepts data in a XYZ format. Prior to map generation, Surfer processes the datal set in such a way that it is converted to data points on an evenly spaced grid by interpolation. The interpolation techniques and the spacing and dimensions of this grid are defined by the user.

A contour map (Figure 2.7) was then generated. To improve the realism and accuracy of the interpolation, additional data points were added where needed. That is, the contour lines of Figure 2.7 should match the contour lines and zones of surface hydrothermal activity seen in Figure 2.6. When the contour map wals found to be satisfactory, the approved datat set was used to generate the threedimensional model (Figure 2.8). This model is intended to represent the shape of the upper surface of the hydrothermal system at Casa 
Diablo. The overall shape of the model is based primarily on the 50 ohm-m surface. Surface hydrothermal features are represented by the small peaks of Figure 2.8 and do not affect the overall shape of the model.

The three dimensional surface of Figure 2.8 does not show the actual shape of the upper surface of the hydrothermal system, but rather the shape it would have with respect to a flat topographic ground surface. This is because each resistivity data point is a measure of depth below surface, regardless of elevation. To correct for the effects of elevation, it was necessary "add in" the elevation at the location where each data point was taken. This was accomplished by first plotting each data point on a topographic map of the area. The data point at the lowest elevation was defined as the zero datum point, and all other points were adjusted accordingly. Then the elevation value at each data point was added to the corresponding value of the depth below the surface to the hydrothermal system. The adjusted data points were then processed by Surfer, providing a more realistic three dimensional surface (Figure 2.9). Although this is not the only modeling technique that may be applied to this data. I believe it does provide a reasonable model of the upper surface of the hydrothermal system at Casa Diablo.

Casa Diablo and Long Valley

There are two features of the three dimensional model and the resistivity contour maps that agree well with the interpretation that other researchers have endorsed (Sorey et al., 1991), concerning the entire hydrothermal system of Long Valley. As mentioned before, this interpretation is that the hydrothermal fluids in Long Valley rise along faults from great depths $(4$ to $6 \mathrm{~km}$ ) to the surface and flow eastward across the caldera just below the surface, eventually emptying into Lake Crowley (Figure 1.2). One of the features that agrees well with this interpretation is the strong resistivity gradient in the far western section of the map area that can be seen in all 
three resistivity contour maps. The other is the continuation of low resistivities to the east beyond the area of surface activity.

I interpret the western gradient to be caused by the near surface upwelling of hydrothermal water from the very deep reservoir, which is the source of most of the caldera's near-surface hydrothermal water. If this is the case, this upwelling zone may power all of the surface activity to the east within the caldera.

It is possible to get a reasonable idea of the angle at which the hydrothermal water rises from the deep reservoir to Casa Diablo. This can be done by using temperature versus depth profiles in wells that have been drilled extensively, albeit sparsely, throughout the caldera. If a well penetrates the hydrothermal system, the depth to it is indicated by a temperature inversion (a sharp increase in temperature that is usually followed by a decrease) on the temperature versus depth profile (Sorey et al., 1991). A good example of this is well M-1 (Figure 2.10) which is located at Casa Diablo and shows a temperature inversion with a peak of 172 degrees Celsius near $100 \mathrm{~m}$ depth below the surface.

Figure 2.11 shows the temperature versus depth profiles of four other important wells that indicate the depth to the hydrothermal system. Figure 2.12 indicates the location of each of these wells together with the section line of Figure 2.13, which is a profile based on the well data and elevation. Figure 2.13 clearly shows that the angle of upwelling is very shallow. Elevation and topography may also play an important role in determining where the hot water will reach the surface. Casa Diablo is located at low elevation on the southern flank of the resurgent dome and is surrounded by slightly higher elevation to the east and west. The relationship between the location of the upwelling hydrothermal water and the low elevation at Casa Diablo make it a favorable area for surface activity to occur, simply because the hydrothermal water is so close to the surface there.

However, there are many other places where the hydrothermal water is very close to the surface, but show no surface activity. It is the faults at Casa Diablo, which are closely associated with surface 
activity (Figure 1.3), that appear to control the locations of active zones in detail. The ground over those areas that have hydrothermal water close to the surface, but that do not have surface activity, is probably sealed off by clay alteration and silica mineralization. If it were not for the periodic fault movement that takes place at Casa Diablo anything more than minor surface activity might be absent. In addition to the location of near surface upwelling, something can be said of the hydrothermal waters horizontal extent. Although resistivities increase north of the western fault, it is possible that the higher elevation there masks the presence of underlying hydrothermal water. Surface activity northward along the eastern fault reveals the northward extent of hydrothermal water, at least along the fault. When the field work of this study was being conducted, it was noted that surface activity extended at least several hundred meters northward along the western fault. A deeper penetrating survey would be needed to determine the initial $\mathrm{N}-\mathrm{S}$ extent of the upwelling in the western section of the map area.

The continuation of the low resistivities to the east is the result of the near surface flow of the hydrothermal water (caused by its buoyancy) all the way to Lake Crowley. The hot pools to the east are a manifestation of this near surface eastward flow, which is caused by the topographic gratient (elevation drops toward the east). Even though hydrothermal fluid is present almost everywhere to the east, as it flows to the east it cools. The hottest hydrothermal fluid will be found along the zone of upwelling as deeply as can be drilled. However, the degree of cooling through the first few hundred meters of lateral flow maly be insignificant, as far as electrical generation is concerned. 


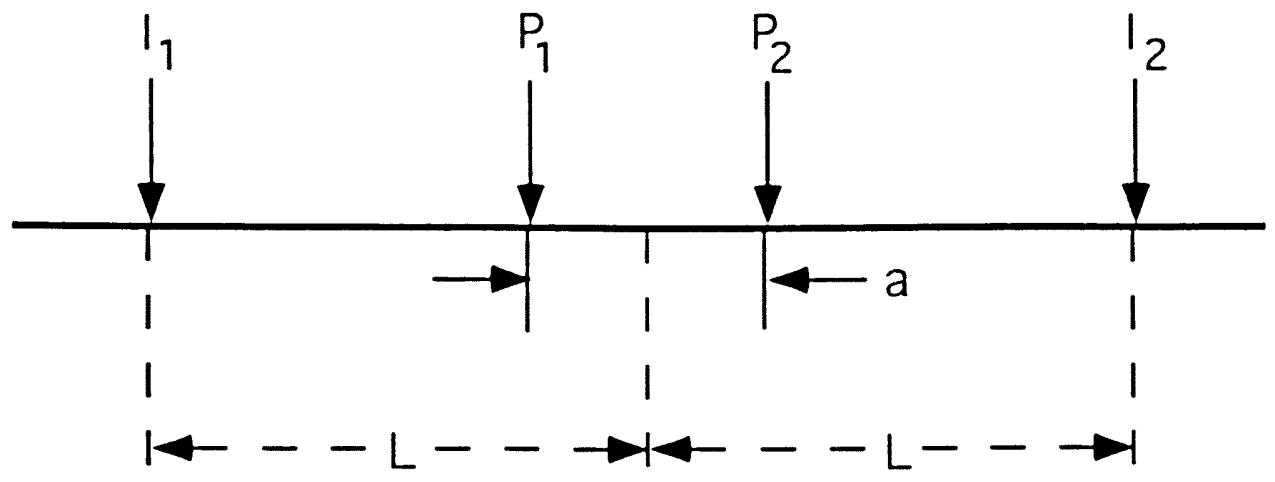

FIGURE 2.1. Electrode arrangement of the Schlumberger array. $\quad I$ = current electrodes; $P=$ potential electrodes. 


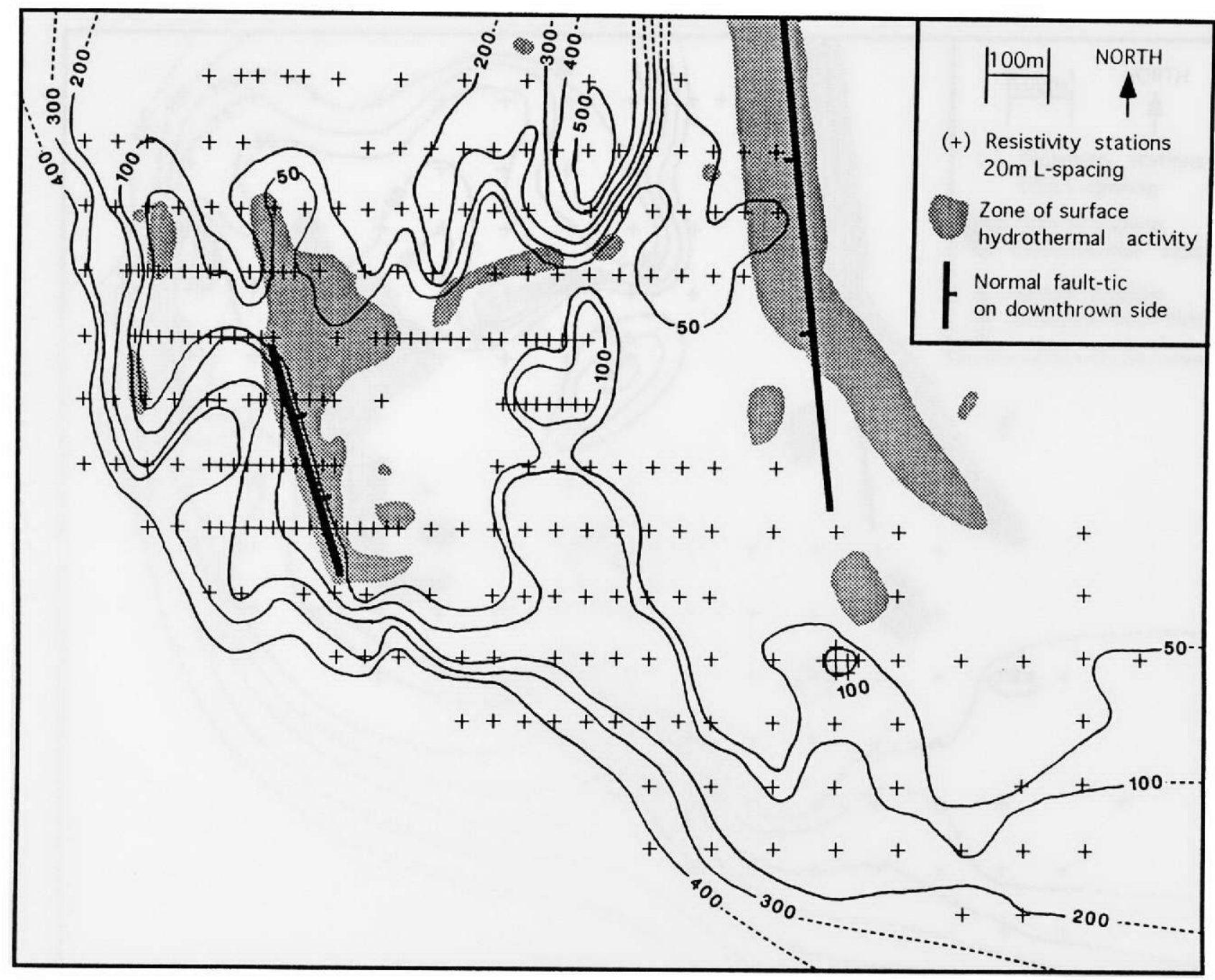

FIGURE 2.2. Contour map of resistivity at an L-spacing of $20 \mathrm{~m}$. 


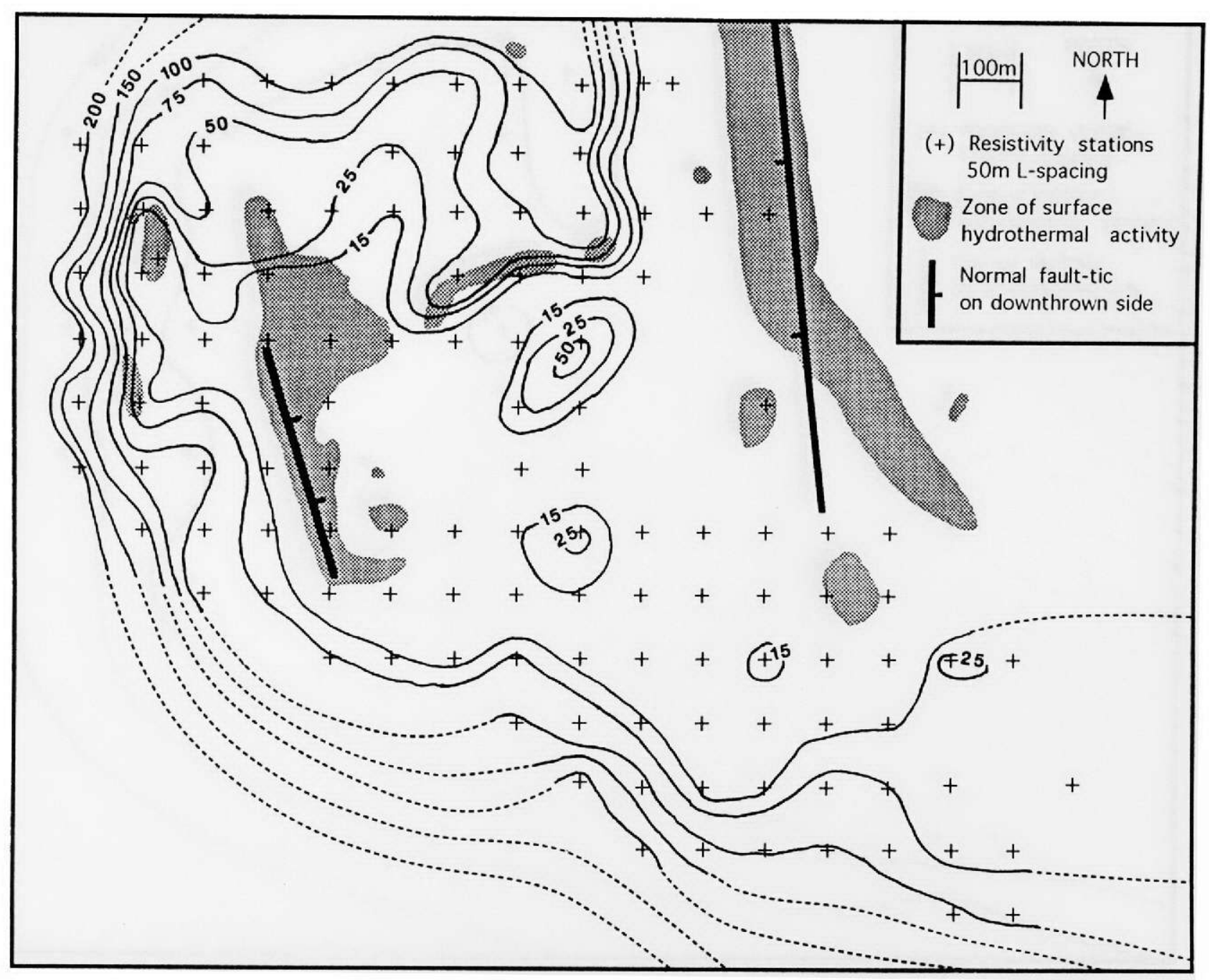

FIGURE 2.3. Contour map of resistivity at an L-spacing of $50 \mathrm{~m}$. 


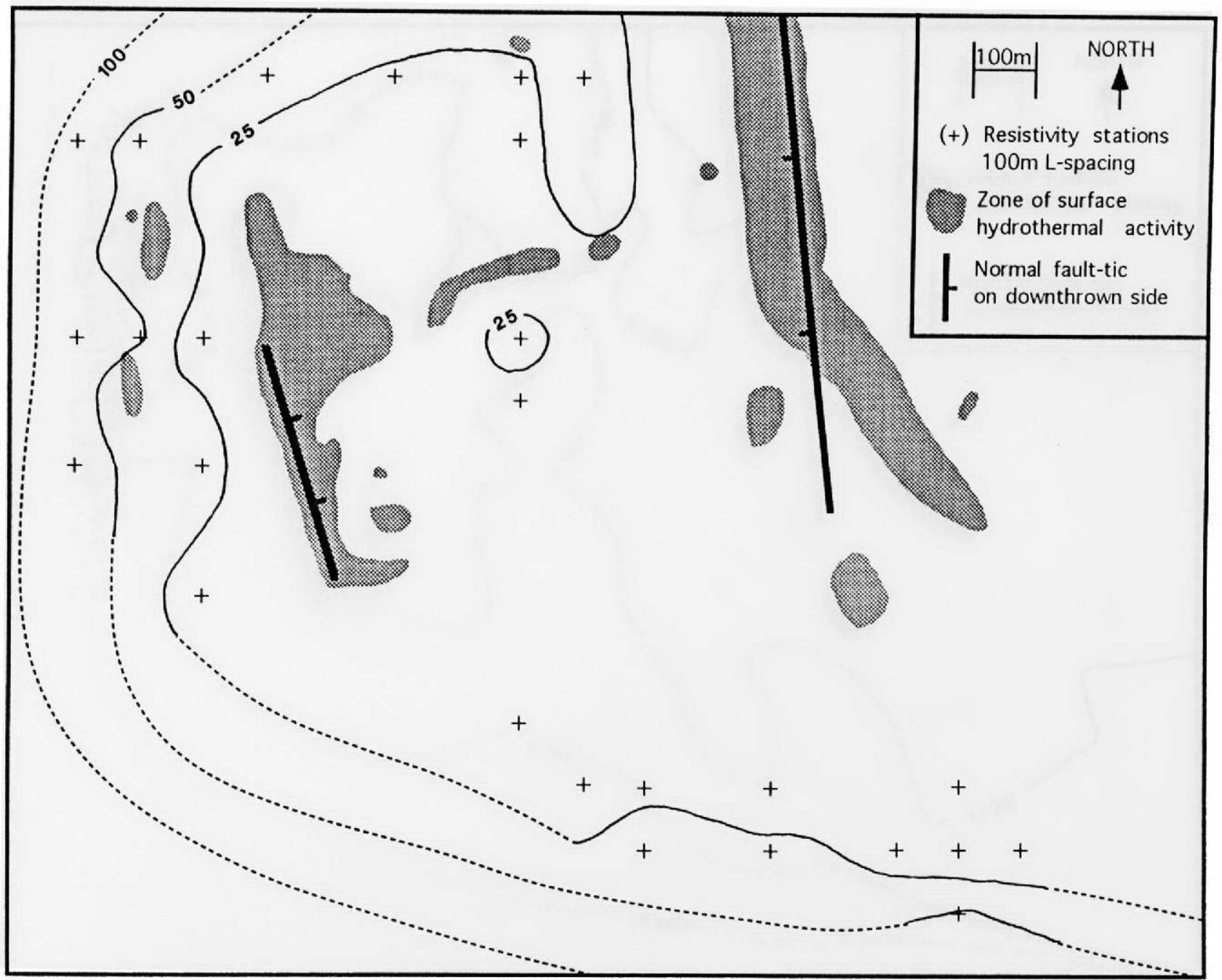

FIGURE 2.4. Contour map of resistivity at an L-spacing of $100 \mathrm{~m}$. 


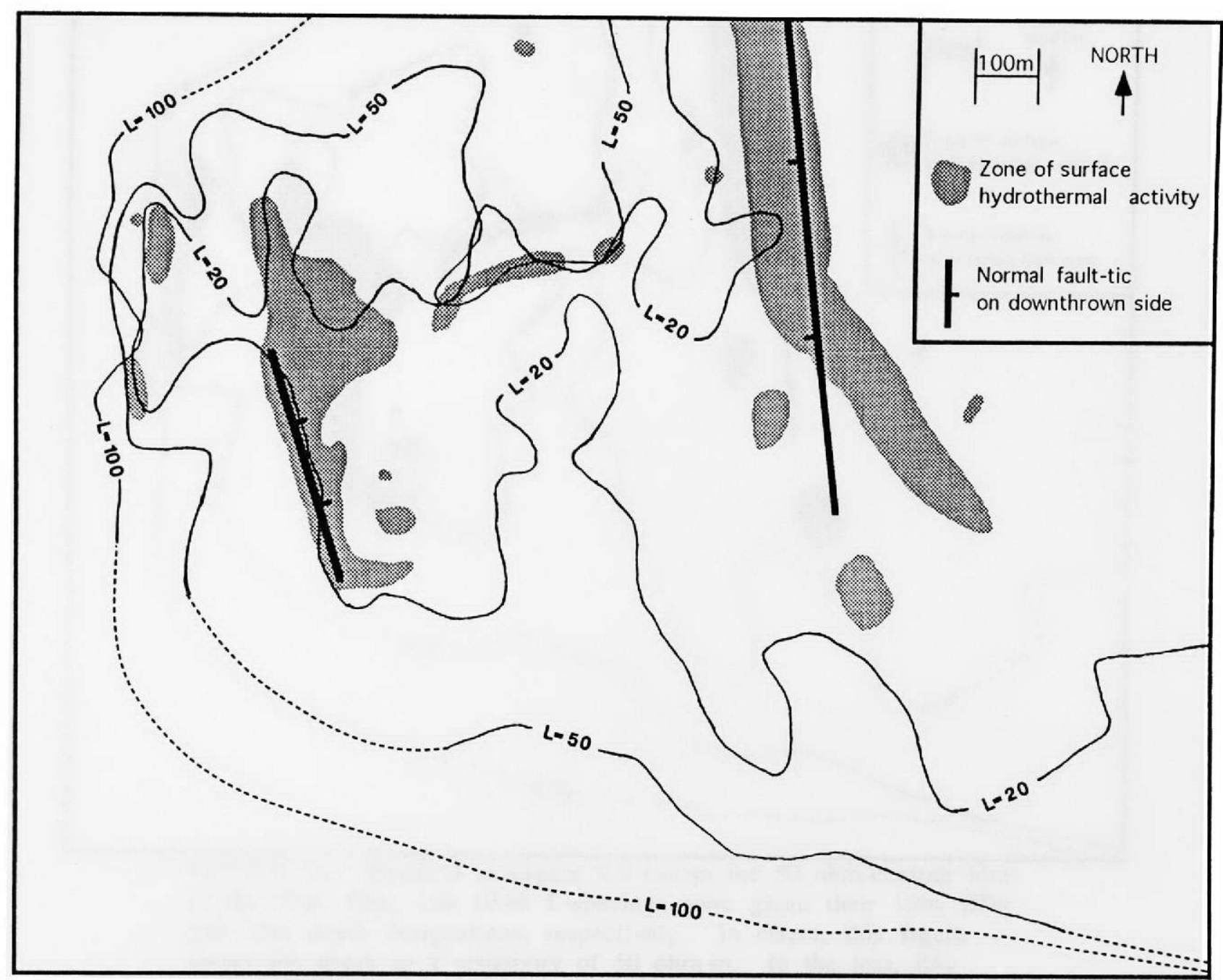

FIGURE 2.5. Superimposed $50 \mathrm{ohm}-\mathrm{m}$ contour lines of $20 \mathrm{~m}, 50 \mathrm{~m}$, and $100 \mathrm{~m} \mathrm{~L}$-spacings. 


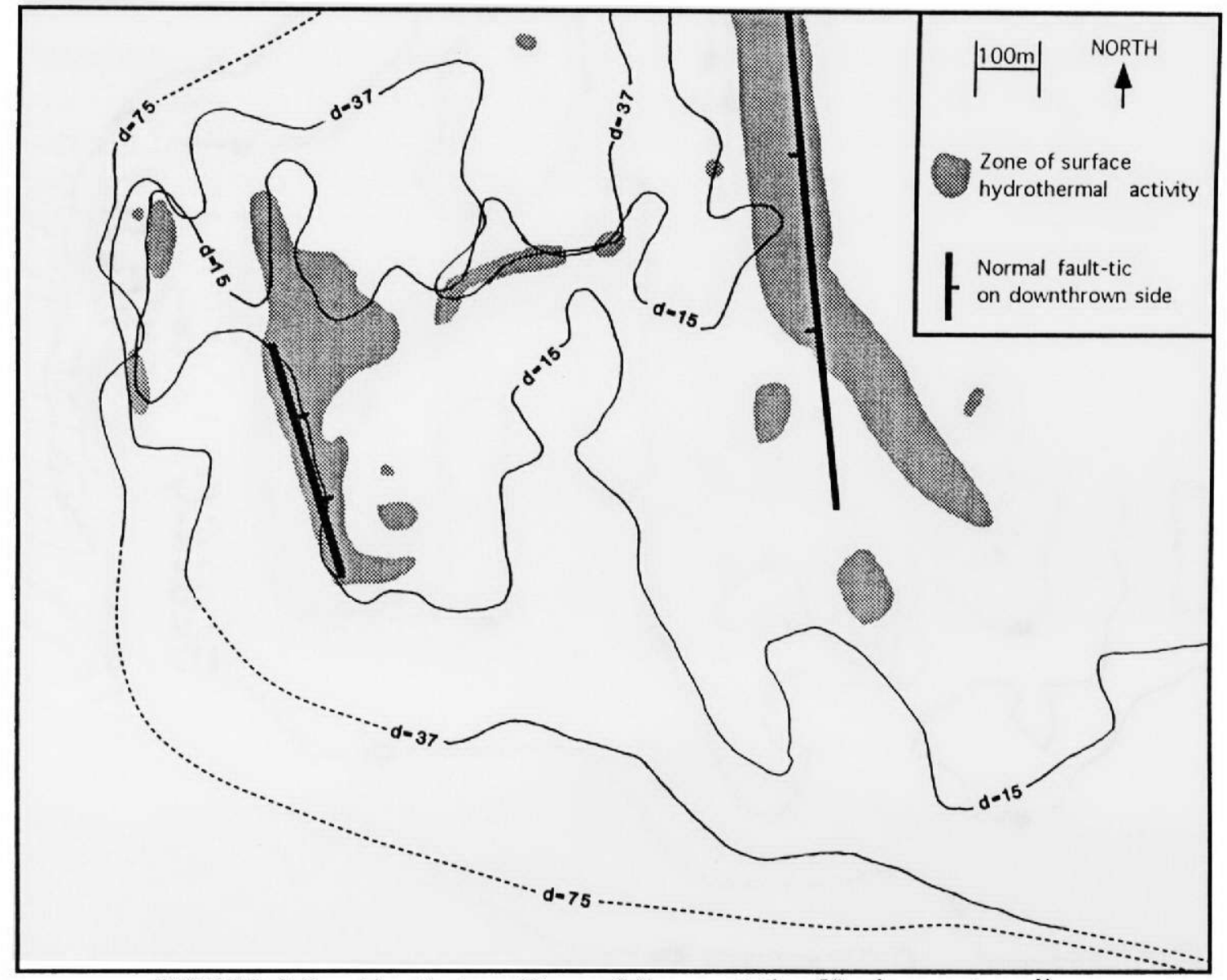

FIGURE 2.6. Identical to Figure 2.5 except the 50 ohm-contour lines of the $20 \mathrm{~m}, 50 \mathrm{~m}$, and $100 \mathrm{~m} \mathrm{~L}$-spacings were given their $15 \mathrm{~m}, 37 \mathrm{~m}$, and $75 \mathrm{~m}$ depth designations, respectively. In effect, this figure shows the depth to a resistivity of $50 \mathrm{ohm}-\mathrm{m}$. In the text, this surface is defined as the depth to ground that is hydrothermally permeated to the extent that it may be considered a part of the hydrothermal system. 


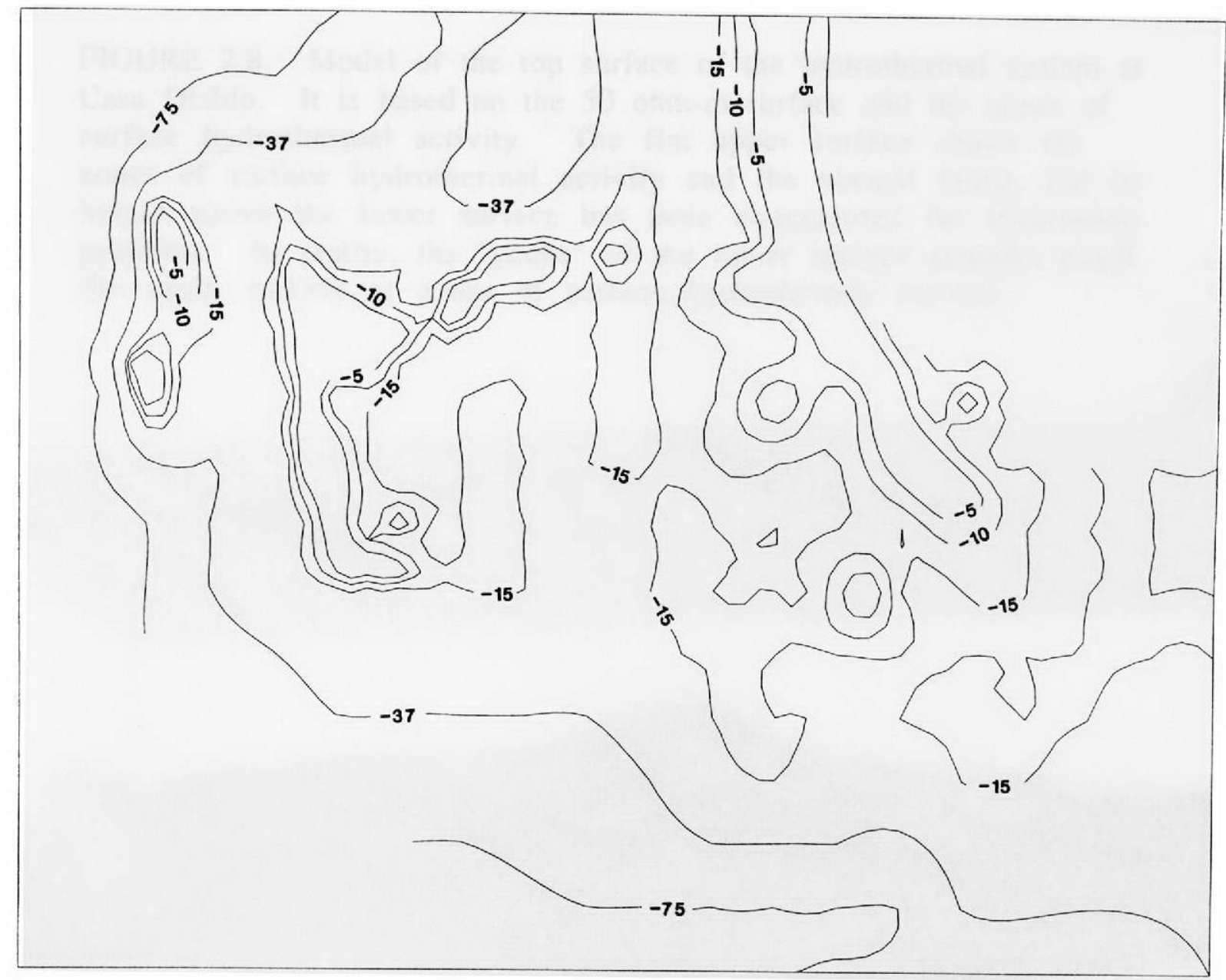

FIGURE 2.7. Contour map of the depth to the hydrothermal system generated by the Surfer contouring program. It is based on the resistivity data and zones of surface hydrothermal features of Figure
2.6 . 
FIGURE 2.8. Model of the top surface of the hydrothermal system at Casa Diablo. It is based on the $50 \mathrm{ohm}-\mathrm{m}$ surface and the zones of surface hydrothermal activity. The flat upper surface shows the zones of surface hydrothermal activity and the normal faults, but its height above the lower surface has been exaggerated for illustration purposes. In reality, the "peaks" of the lower surface actually touch the upper surface at zones of surface hydrothermal activity.

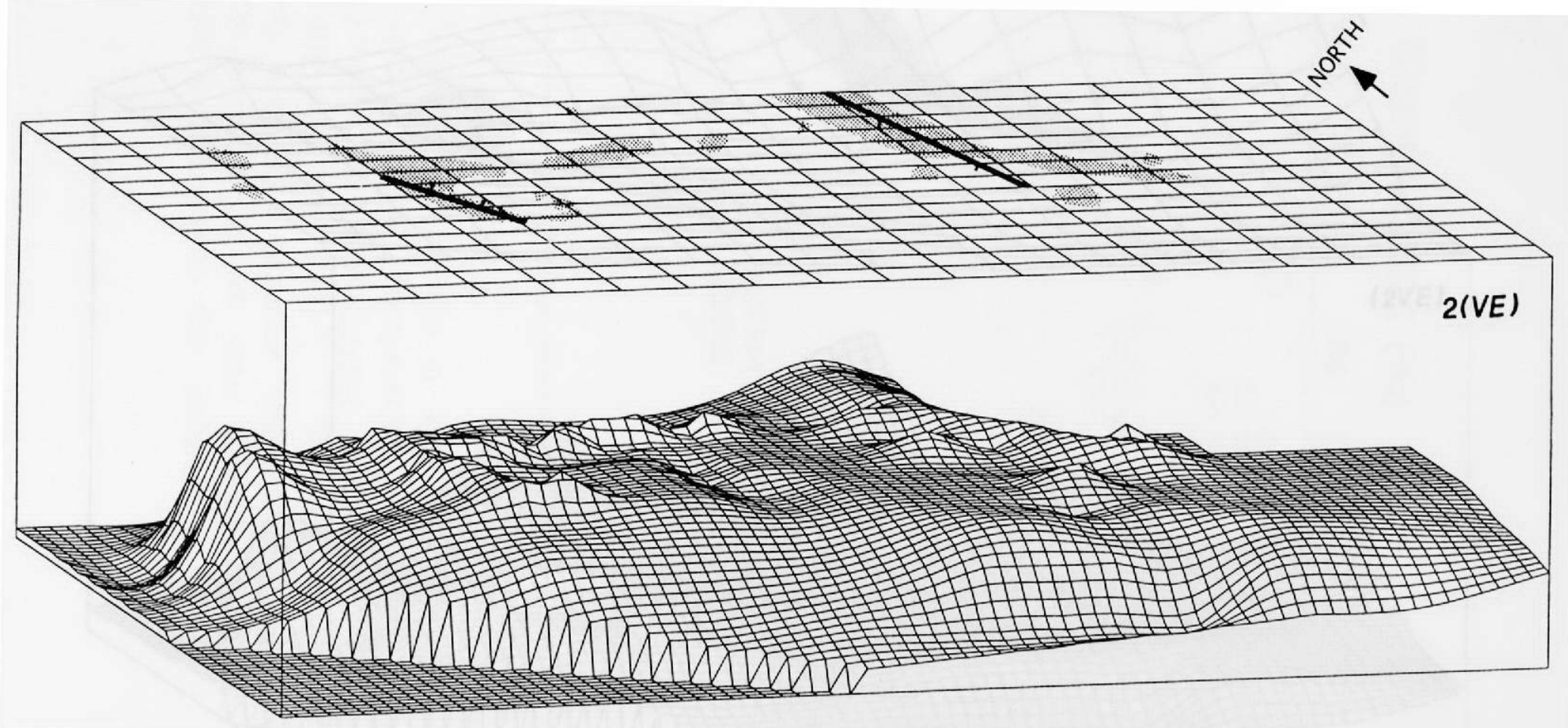


FIGURE 2.9. Same as Figure 2.8 except that topography is taken into consideration in this model of the surface of the hydrothermal system.. As in Figure 2.8, the height of the upper surface has been exaggerated above the lower surface.

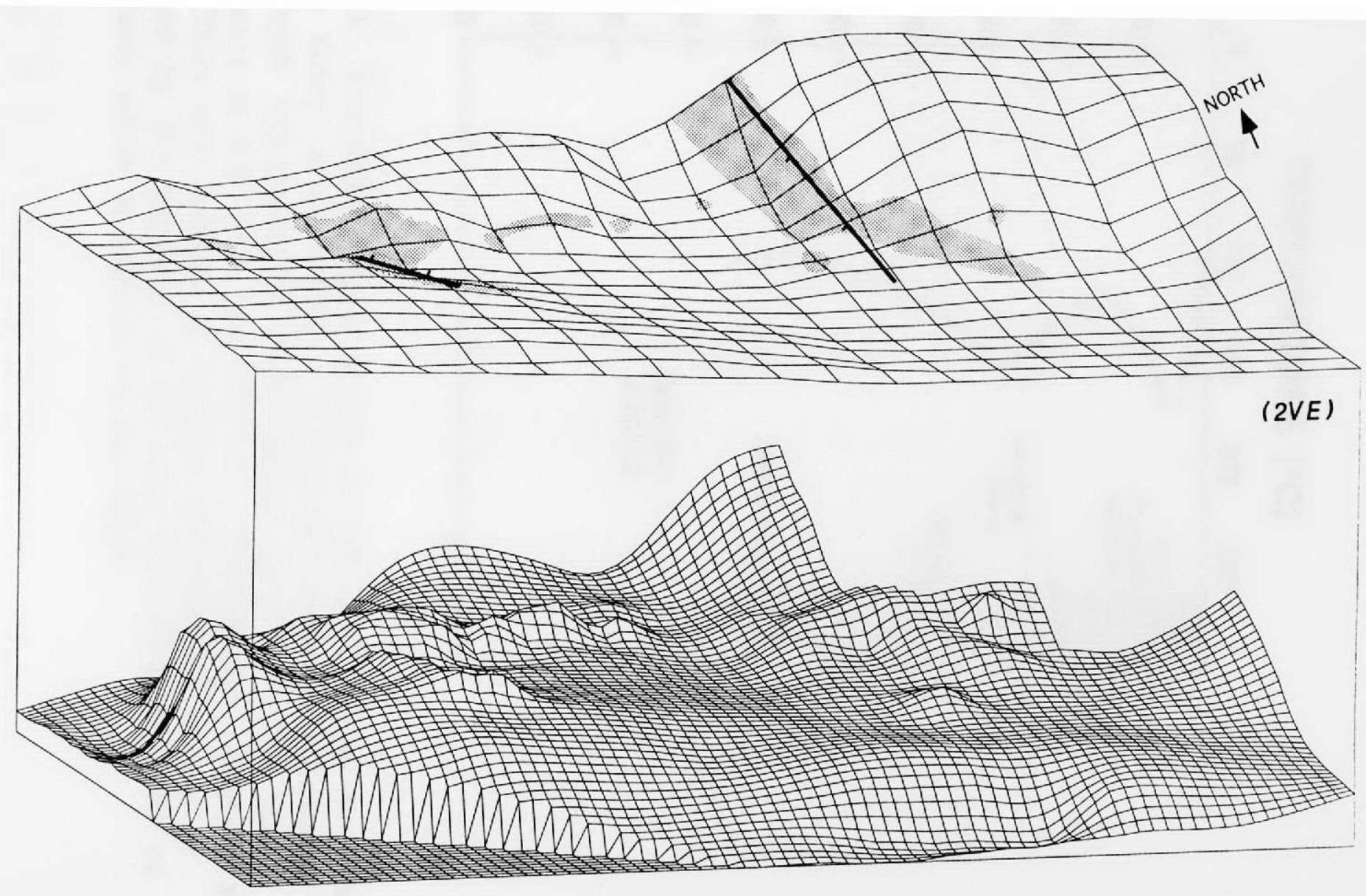




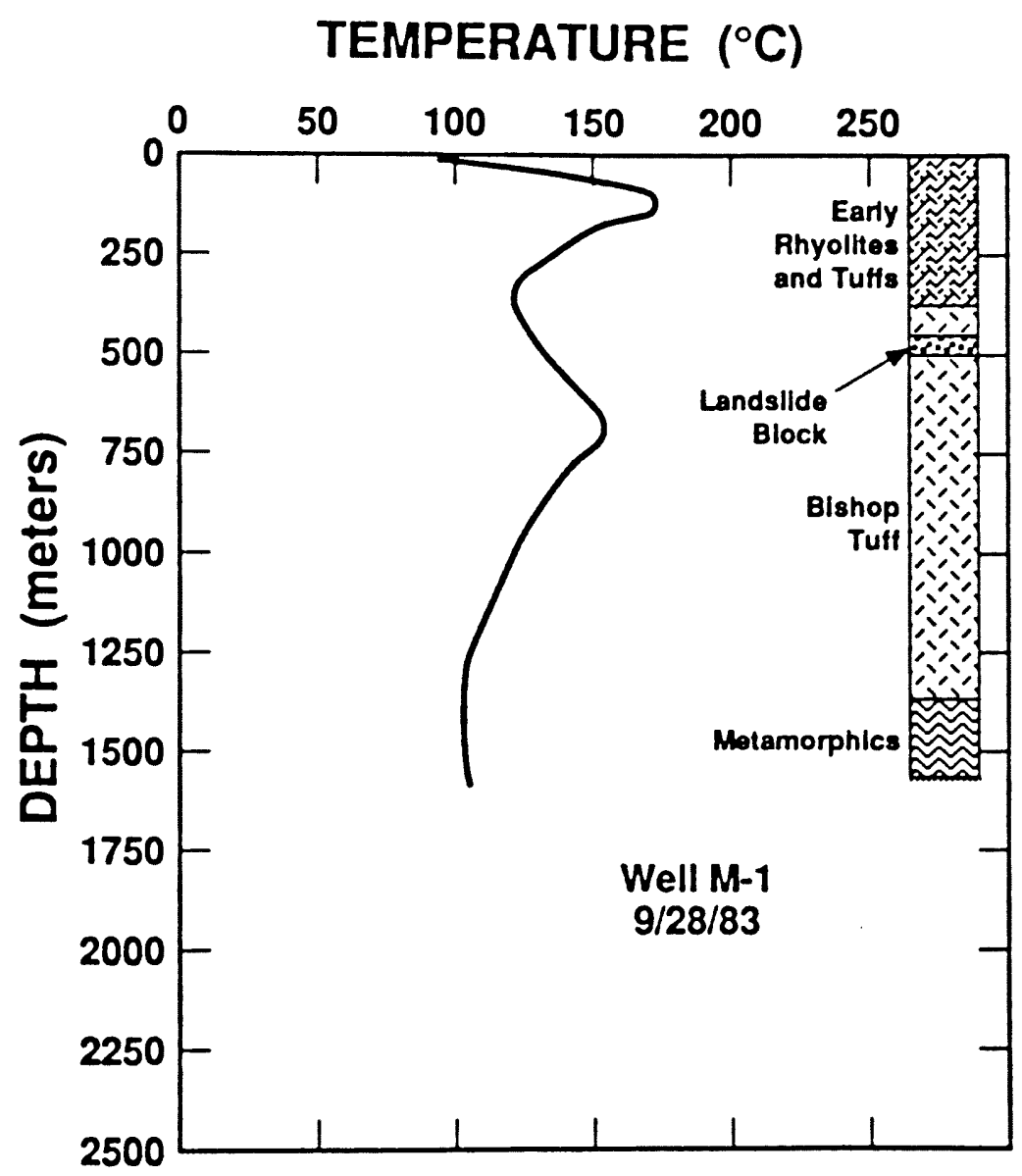

FIGURE 2.10. Temperature-depth profile of well M-1 located at Casa Diablo (from Sorey et al., 1991). Temperature inversion between 0 and $250 \mathrm{~m}$ depth represents the hydrothermal system of this study. Peak temperature at this time was $170{ }^{\circ} \mathrm{C}$. Temperature inversion at a depth of $700 \mathrm{~m}$ may indicate a separate hydrothermal system of may be caused by the injection of the spent hydrothermal water of the power plants which is injected to this depth. 
TEMPERATURE $\left({ }^{\circ} \mathrm{C}\right)$
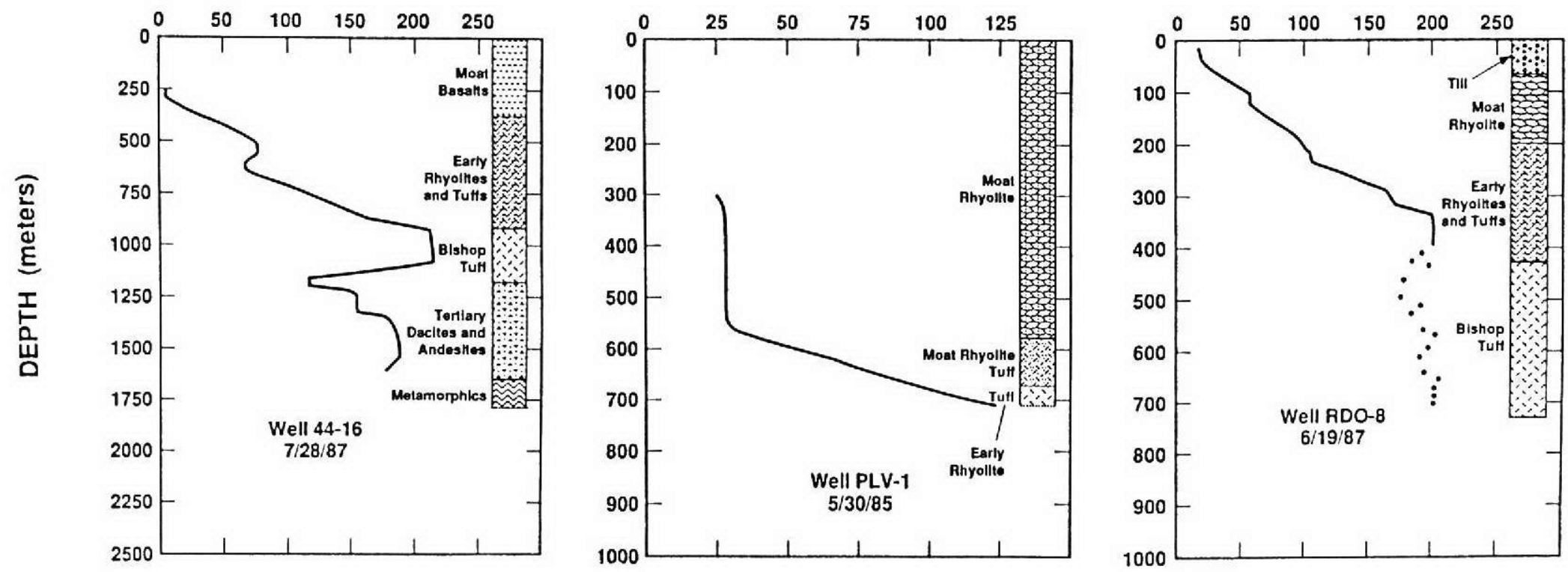

FIGURE 2.11. Temperature-depth profiles of three important wells that penetrate in or near the hydrothermal system of Long Valley that includes Casa Diablo (wells 44-16, RDO-8, and PLV-1 from Sorey et al., 1991) Figure 2.12 denotes the location of each well. 


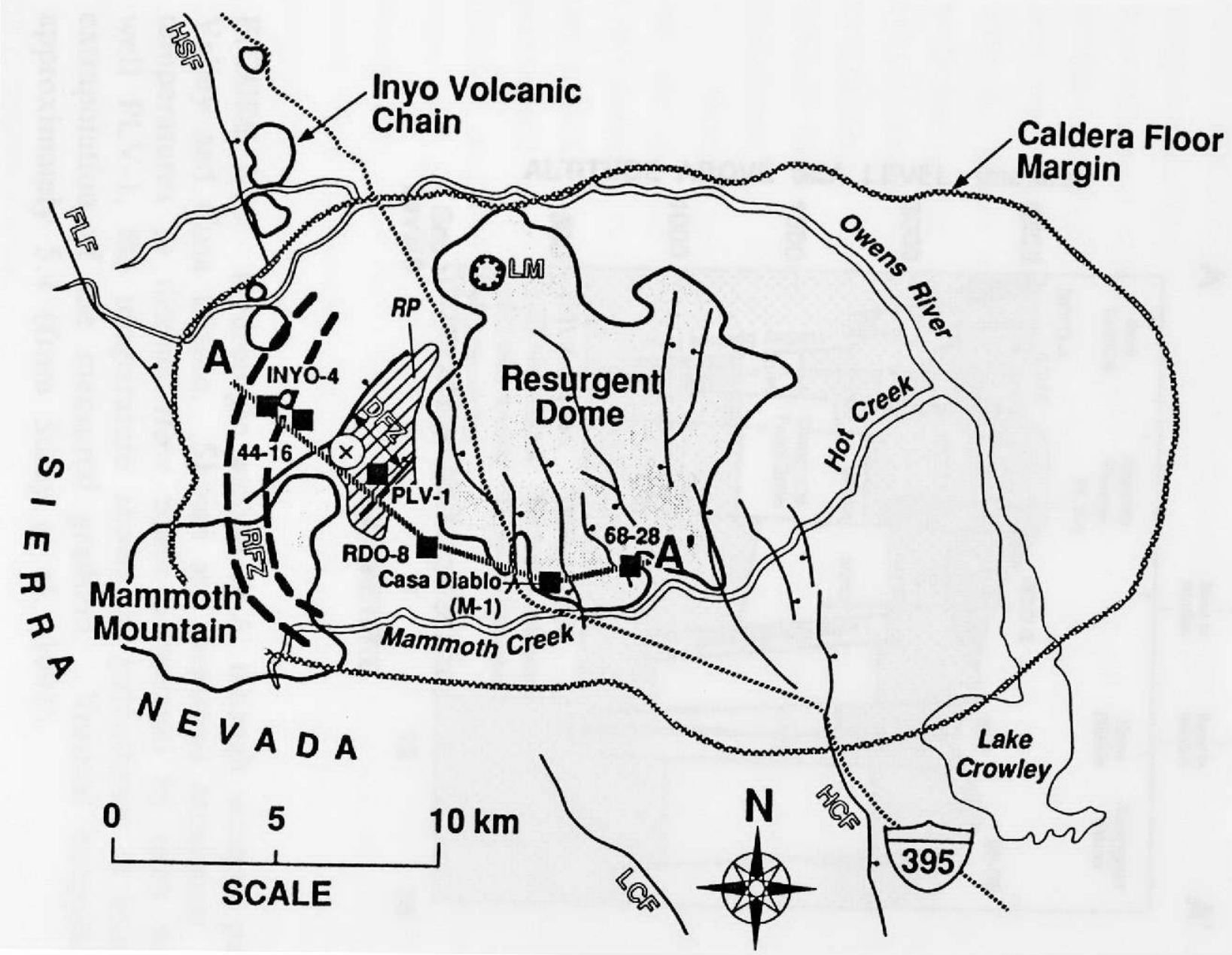

FIGURE 2.12. Map showing location of the four wells of Figures 2.10 and 2.11, and the section line A-A' of Figure 2.13 (from Sorey et al.,
1991 ). 


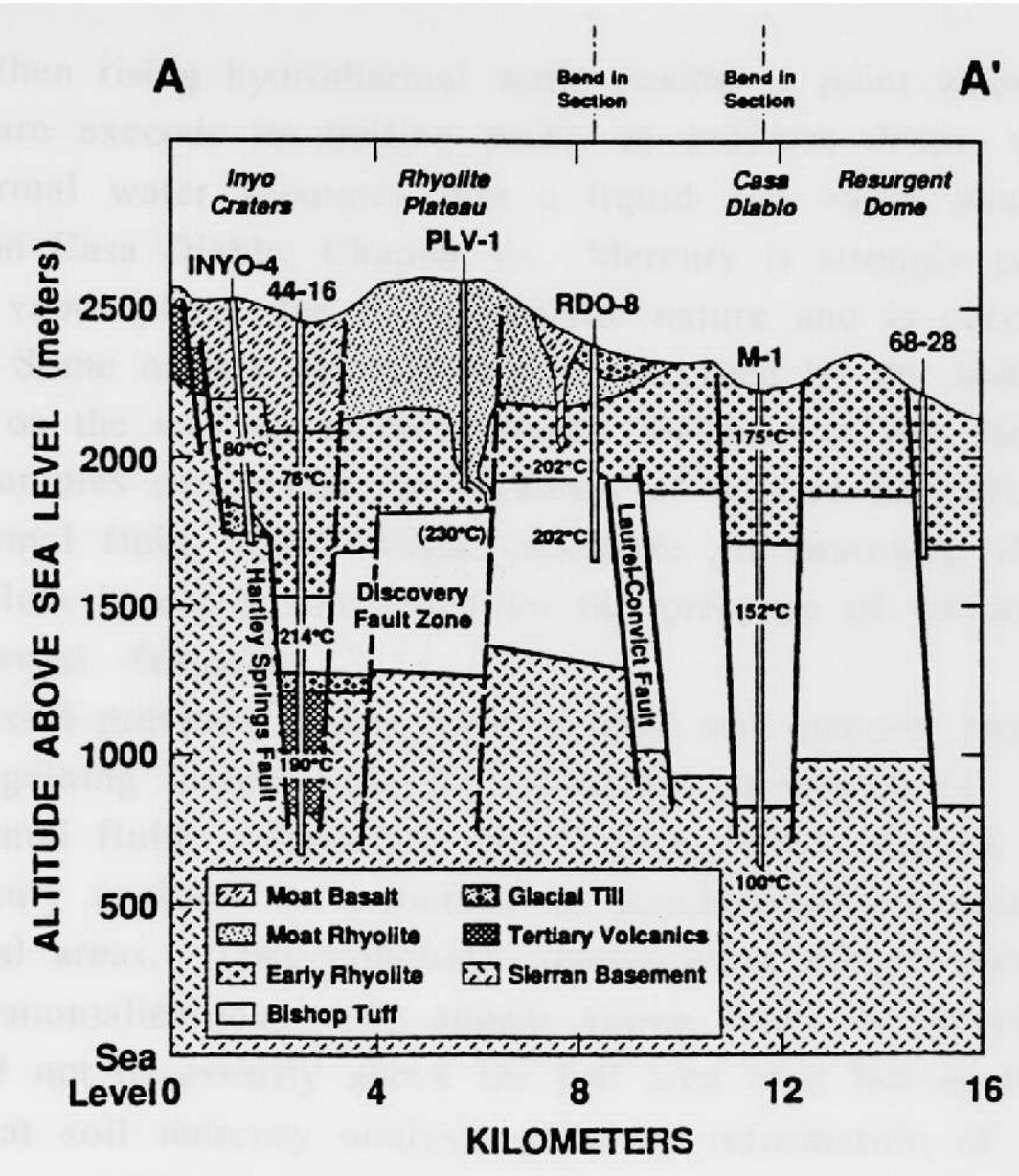

FIGURE 2.13. Hydrologic section A-A' through western part of Long Valley and Casa Diablo. Shown are measured maximum temperatures in thermal-flow zones penetrated by each well. For well PLV-1, the temperature shown in parentheses is based on an extrapolation of the measured gradient. Vertical exaggeration is approximately 5.4 (from Sorey et al., 1991). 


\section{CHAPTER 3: MERCURY ANALYSIS}

\section{INTRODUCTION}

When rising hydrothermal water reaches a point where its temperature exceeds its boiling point, as pressure drops, the hydrothermal water separates into a liquid and vapor phase (see section on Casa Diablo, Chapter 1). Mercury is strongly partitioned into the vapor phase due to its volatile nature and is carried upward with it. Some of this mercury is then adsorbed by the surface of soil particles on the way up to the surface. Because of this fact, analyses of soil samples can reveal the locations of upward migration of hydrothermal fluid, which might otherwise go unnoticed if the upward flow is not accompanied by the presence of surface hydrothermal features.

Several previous studies have utilized soil mercury analysis as a tool for gaining insight into the subsurface movement of hydrothermal fluid. Varekamp and Buseck (1983) discuss the use of soil mercury analyses as a method of geochemical exploration in geothermal areas. They conclude, among other things, that soil mercury anomalies may only appear above zones of upwelling hot water and not necessarily above the full area of a hot aquifer. This means that soil mercury analysis provides information of a different nature than resistivity profiling. Whereas resistivity profiling reveals the extent of a hydrothermal system without regard to its movement, soil mercury analysis indicates locations of its upward flow. The insight soil mercury analyses provide concerning hydrothermal fluid dynamics can be of a great value for any study in which the description of a hydrothermal system is important.

\section{FIELD TECHNIQUES}

A total of 144 soil samples were taken along a partial $100 \mathrm{~m}$ grid through July and August of 1992 for subsequent Hg concentration analysis (Figure 3.1). Virtually all Hg sample points lie along the 
same traverses and stations that were used for the resistivity surveys (Chapter 2). The samples were taken from $15 \mathrm{~cm}$ below the surface, and were composed mainly of pyroclastic-type sediments of sand to pebble size, mixed with a more fine-grained organic poor component. Unsorted soil was put into glass vials, tightly capped, and stored in a cool location for later analysis.

\section{LABORATORY TECHNIQUES}

Just prior to analysis, soil-Hg samples were air dried overnight in a cool area (about $75^{\circ} \mathrm{F}$ ), and then sieved with an $80 \mathrm{um}$ mesh stainless steel sieve. One gram of the sieved fraction from each sample was placed in glass scintillation vials for the analysis of elemental mercury. One $\mathrm{ml}$ of concentrated hydrochloric acid was added to each vial and left for four days for the acid to completely digest the mercury. Twenty $\mathrm{ml}$ of deionized, distilled water was then added to the soil samples and left for two days for complete settling of the solution. Five $\mathrm{ml}$ of this acid solution was then placed in $20 \mathrm{ml}$ plastic vials to which $10 \mathrm{ml}$ of distilled deionized water was added and made ready for analysis. Some samples had such high levels of mercury that further dilution was necessary.

The samples were then analyzed for mercury using a Merlin Fluorescence Detector in the Department of Civil and Environmental Engineering at Florida International University. The digested samples are reacted with acidic stannous chloride to convert any $\mathrm{Hg}^{2+}$ present into Hg vapor. The mercury vapor is removed from the solution by a stream of argon, and the mercury is detected by atomic fluorescence. The Hg-Merlin Fluorescence detector is sensitive to mercury concentration down to 1 part/trillion.

\section{RESULTS}

Figure 3.1 shows the soil mercury concentration, in parts per billion by weight ( $\mathrm{ng} / \mathrm{g}$ ), at each of the 144 sample point locations. As before, the shaded areas enclose zones of surface hydrothermal 
activity. An initial examination suggests a relationship between high soil mercury concentrations and surface hydrothermal activity. At this point, however, a statistical analysis of the data is needed to better analyze this relationship.

Statistical Treatment of Data

A statistical analysis of the soil-mercury data was performed using the procedures outlined by Lepeltier (1969) and Sinclair (1974). The data was first plotted on log probability paper and examined for the presence of straight segments which can indicate the presence of individual populations. This is because the distribution of the datat points of an individual population is normally representable as a bell curve. When a bell curve is plotted on a logarithmic scale is plots as a straight line.

Figure 3.2 is a log probability plot of the mercury data and reveals that there are three straight segments suggesting the presence of three populations. Best fit lines were drawn through each segment. The total datal set was then divided where the best fit lines cross each other, at the 22 and 80 ppb levels. These separation points do not themselves accurately define the extremes of the three populations, although they are fair approximations. For a more statistically supported separation a further step must be taken.

The three newly separated datal sets, separated at 22 and $80 \mathrm{ppb}$, were each plotted on log probability paper in the same manner as the total data set (Figure 3.3). Best fit lines were then drawn through the three replotted segments and represent the distributions of the three populations that together make up the total data set. The accuracy of this three population model was checked by adding the probabilities of the three populations at several ppo levels using the formula:

$P_{m}=f_{A} P_{A}+f_{B} P_{B}+f_{C} P_{C}$ 
where $\mathrm{Pm}$ is the probability of the mixture; $\mathrm{P}_{\mathrm{A}}, \mathrm{P}_{\mathrm{B}}$, and $\mathrm{P}_{C}$ are the probabilities of the populations $A, B$, and $C$ at a specific ppb level; $f_{A}$, $f_{B}$, and $f_{C}$ are the proportions of populations $A, B$, and $C$. The best fit lines were adjusted until the check points showed the best possible match to the original probability plot. The "O" marks on Figure 3.3 are the check points themselves and indicates that the three population model effectively explains the distribution of the complete data set.

The three populations are referred 10 as (1) anomalous, (2) aureole (an anomalous zone surrounding a stronger anomaly), and (3) background and given the designations of $A, B$, and $C$, respectively. Percentiles of $1 \%$ and $99 \%$ were chosen in order to locate the limits or thresholds of each population (Table 3.1). Population C (background) has a $99 \%$ limit of $60 \mathrm{ppb}$, which means that $99 \%$ of all the data that belongs to the background population is of a concentration of less than $60 \mathrm{ppb}$. This, in turn, means that any value above $60 \mathrm{ppb}$ is almost certainly not background and therefore anomalous.

Population B (aureole) however, has a lower $1 \%$ limit at 9 ppb, which means that much of the data with values less that $60 \mathrm{ppb}$, but no less than 9 ppb, belong to the aureole rather than the background population. In addition, the geometric mean (50) percentile) of the background population is only $7 \mathrm{ppb}$, whereas the geometric mean of the aureole population is $35 \mathrm{ppb}$. Therefore, concentrations between 9 and 60 ppb are potentially anomalous (a mixture of anomalous and background values). and, as stated before, concentrations of 60 ppb or greater are almost certainly anomalous.

Although it might be reasonable to pick some arbitrary value between 9 and 60 as the dividing point for the separation of anomalous from background data, confidence would be sacrificed. Instead, both the 9 and 60 ppb levels were chosen for contouring (Figure 3.4). This is acceptable as long as the uncertainty of the 9 $\mathrm{ppb}$ contour is understood. As predicted, contouring the data at these levels clearly shows that most values between 9 and $60 \mathrm{ppb}$ 
are closely related to those values which are certainly anomalous (above $60 \mathrm{ppb}$ ).

\section{DISCUSSION OF MERCURY ANALYSES}

An examination of Figure 3.4 reveals that the mercury anomaties and the zones of surface hydrothermal activity correlate well. This correlation is expected if the cause of both the mercury anomalies and the surface activity is rising hydrothermal fluid. In addition to the areas where there is good correlation of mercury anomalies and surface activity, there are some locations that show a disparity. Virtually every location of surface activity gives rise to a corresponding mercury anomaly as expected, becatuse of the boiling, but the opposite is not true. Explatining the presence of these mercury anomalies is more difficult beciase there is no obvious boiling there.

There are two major anomalous areas where this lack of correlation exists. One is the erratically distributed anomalous region between the two faults, which will be referred to as the central anomalies. The second is the more continuous anomalous zone located in the extreme southeastern section of the map area, and will be referred to as the southeastern anomalous zone.

The possibility that these anomalous areas were caused by a previous episode of surface activity and/or hydrothermal alteration was considered, but rejected. There are two reasons for this. First, petrographic analysis demonstrates that the soil samples from anomalous areas that lacked surface hydrothermal activity show only the slight weathering that is nomal for the whole area (Figure 3.5). They do not show the strong hydrothermal alteration that soil near active surface hydrothermal features is characterized by.

Secondly, a previous study of this area, discussed more fully below, showed that mercury anomalies can develop and disappear in less than seven years (Varekamp and Buseck, 1984). In light of this short residence time and the known lack of any recent surface activity at these particular locations, it would appear to be an 
impossibility that these anomalies are a consequence of past activity.

Another possibility is that ground water flow has mobilized the soil mercury in hydrothermally active zones and transported it to these anomalous areas. If this were the case, it would seem likely that mercury anomalies formed in this manner would show transitional pattern of concentration in some preferred direction. The central anomalies and the southeastern anomaly show no such pattern (Figure 3.4). Instead, soil mercury concentrations in these anomalies vary wildly from one sample point to the next. The cause of such variability is better explained by varying degrees of upward vapor flow at these locations.

\section{The Central Anomalies}

The anomalous area between the faults is consistent with the often erratic nature of fault induced mercury anomalies, as described by Klusman and Landress (1979). Their study included traverses across a number of faults in Long Valley, including the eastern fault of this study, and showed that the mercury concentration in soil samples taken across fatuls often was not at a peak value directly over the fault (Figure 3.6). In fact, in some cases the peak concentrations were found as much as $500 \mathrm{~m}$ from the fault. This indicates that the upward movement of hydrothermal fluid near a fault is not limited to the fault itself.

At Casa Diablo the faults provide the main conduits to the surface, but some of the rising vapor may migrate away from the faults through permeable near-surface rock and soil, giving rise to the central anomalies. The central anomalies can be explained by vapor rising to the surface too diffusely for a noticeable surface hydrothermal feature to form.

There is another possible cause of the central anomalies. Fault motion may have strained the nearby surrounding rock enough to create fractures and these maly permit hydrothermal fluid to move away from the faults to the surface. Such fractures may also 
provide conduits to the surface from the hydrothermal water table itself. The lack of surface activity can be explained if the fractures are not so permeable as to allow large volumes of hydrothermal fluid to rise to the surface and form surface hydrothermal features.

Taking into account their erratic distribution, the central anomalies probably result from flow from minor fractures that are drawing hydrothermal fluid away from the faults or more directly from the hydrothermal water table itself. Also, fractures can explain the presence of several zones of surface hydrothermal activity that are found up to $40(0 \mathrm{~m}$ from the faults (Figure 3.4).

\section{The Southeastern Anomaly}

An alternative model is needed to explain the presence of the extreme southeastern anomaly, which appears to be too far from the faults to be caused by dispersion or fractures related to the faults. Although this study includes sample points no more than $700 \mathrm{~m}$ south of the southernmost extension of the eastern fault as mapped by Bailey and Koepper (1977), a previous study by Varekamp and Buseck (1984) showed that a broald mercury anomaly extended southward from this region up to $4 \mathrm{~km}$ south of Old Highway 395 , in 1975 (Figure 3.7). A second survey, performed in 1982 (Figure 3.7), revealed that this southern extension had disappeared, and that anomalous samples in this area were restricted to the north side of Old Highway 395. The coarse sampling of data points in the study by Varekamp and Buseck, which was necessary as it involved the entire caldera, makes a detailed comparison of its anomalies to this studies anomalies difficult. It does suggest the possibility, however, that the southeastern anomaly in this study is part of a much larger and perhaps periodic phenomenon.

Several possible explanations for the presence of this anomaly are considered. First, several studies dealing with hydrothermally active areas have suggested that mercury anomalies might be used to delineate faults hidden by surface material (Varekamp and Buseck, 1983; Connor, 1989) The idea is that the faults high 
permeability, which can allow mercury vapor to reach the surface more easily, reveals its presence. This is probably not the case here because the 1975 anomaly of Figure 3.7 is about $3 \mathrm{~km}$ wide! It would be more reasonable to explain the smaller southeastern anomaly of this study ats a product of a covered southern extension of the eastern fault of Figure 3.4.

On the other hand, the anomalies of both studies may be better explained by topography. Figure 3.8 is a topographic map of the area surrounding Casa Diablo. It shows that the southeastern anomaly of the present study and the 1975 anomaly, lie on a topographic low. Most of the other mercury anomalies, to the east of Casa Diablo, in the 1975 and 1982 studies are located at topographic lows. It may be that the proximity of the surface soils to the hydrothermal water table in these areas could explain the mercury enrichment seen. This cause and effect relationship is somewhat supported by Figure 3.9, which is a map showing the 50 ohm-m contour line of the $20 \mathrm{~m}$ L-spacing resistivity survey superimposed on the soil mercury anomalies. The correlation of near surface hydrothermal fluid and soil mercury enrichment is evident.

What may be causing the present southeastern anomaly is a broad near surface lens of hot water that is boiling just enough to develop the modest mercury anomaly found there. This hot water could have migrated southward from the primary upwelling zone near the western fault of the map area, as the resistivity data suggest (see Chapter 2, Figure 2.5).

In this respect. the 1975 anomaly could have been induced by a period of more vigorous or extensive southerly flow. This may have been caused by a stronger period or intense pulse of upwelling from the upwelling zone near the western latult, or perhaps just a shift of the flow pattern. The degree of southerly flow in this area should also be strongly influenced by the cold water table, which is of meteoric origin. Long or short term variations in the amount of precipitation throughout the region mat exercise a great deal of control over many aspects of the hydrothermal system. For 
instance, fluctuations in the level of the cold water table may affect the direction and extent of hydrothermal flow and the mixing of hot and cold water. This, in turn, could affect the location and degree of boiling.

Mammoth Creek flows eastward along the southern border of the map area of this study. The associated groundwater flow of Mammoth Creek should influence the movement of hydrothermal water spreading southward from the upwelling zone near the western fault. Following periods of high precipitation the cold water table should rise and inhibit the southerly flow of hydrothermal water. Conversely, lower precipitation should lead to drop of the cold water table, permitting a more extensive flow of hydrothermal water.

Table 3.2 shows precipitation al Lake Mary which is located about $8 \mathrm{~km}$ to the southwest of Casa Diablo. The lake feeds Mammoth Creek which flows northward and then eastward toward Casa Diablo. From July, 1974 to June, 1975, the period preceding the 1975 sampling of Varekamp and Buseck and the large southern extension of the Casa Diablo mercury anomaly, the total precipitation was 26.50) inches. From July, 1981 to June, 1982, the period preceding their 1982 study which showed that the mercury anomaly was restricted to the north side of Highway 395, the total precipitation was 42.58 inches, nearly twice as much during 197475. This is consistent with the hypothesis that the cold water table can influence the flow of hydrothermal water. Further work is needed to confirm this relationship, however. An examination of possible records of the water table near Mammoth Creek and Casa Diablo would provide more direct evidence.

In any case, why this increased boiling did not lead to the formation of surface hydrothermal activity in these areas must be addressed. Perhaps an unfaulted, impermeable layer could prevent large volumes of hydrothermal fluid from reaching the surface. Alternatively, thick accumulations of permeable sediments may effectively disperse the upward flowing vapor, as opposed to concentrating it as a fault or fracture can do in an impermeable 
zone. If the southward flow of hot water is not continuous and rare, a hydrothermally altered, impermeable layer may not have yet developed. Another factor that must be considered is the mixing of the hot water with the cooler near surface meteoric water to the south. This mixing may contribute to the lack of surface activity through cooling, but the hydrothermal-meteoric water mixture must still be hot enough to boil if a mercury anomaly is to develop. 


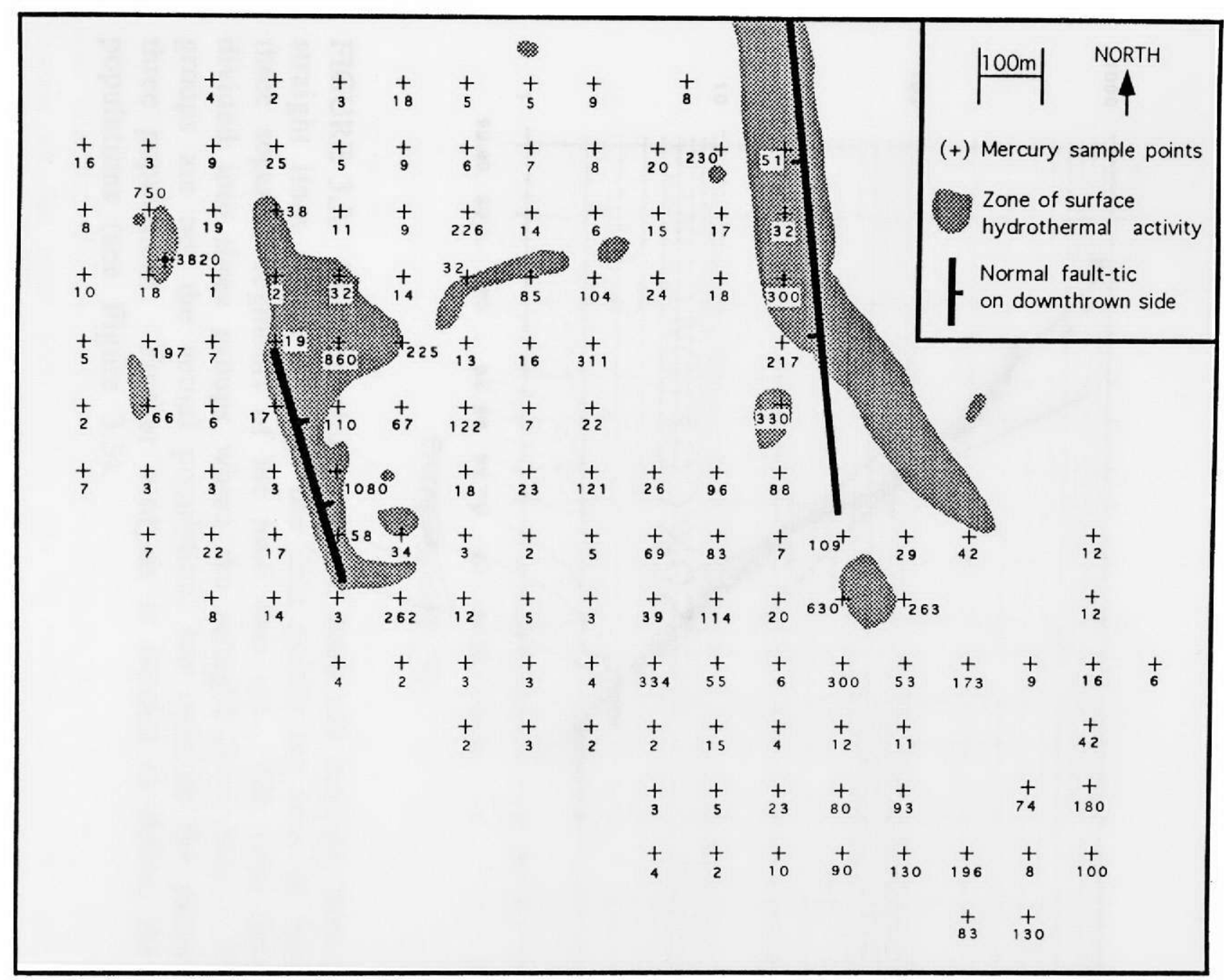

FIGURE 3.1. Map of soil mercury sample locations with concentration in ppb by weight. 


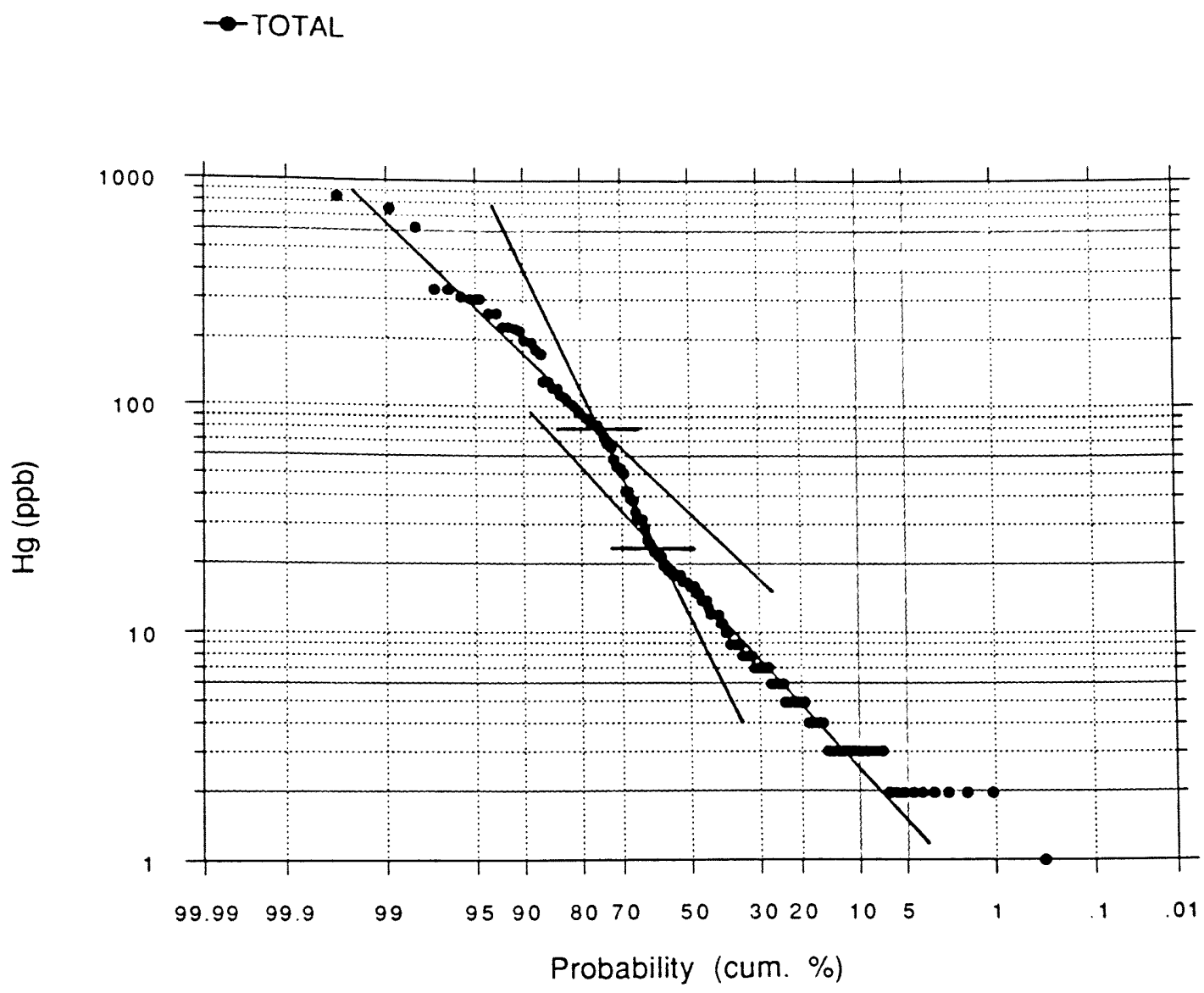

FIGURE 3.2. Log probability plot of total soil mercury data set. The straight lines drawn through the data points are best fit lines to the three separate segments of the total data set. The total data set is divided into three groups where the straight lines cross. These groups are not the actual population, but indicate the presence of three populations. Further analysis is needed to define the populations (see Figure 3.3). 


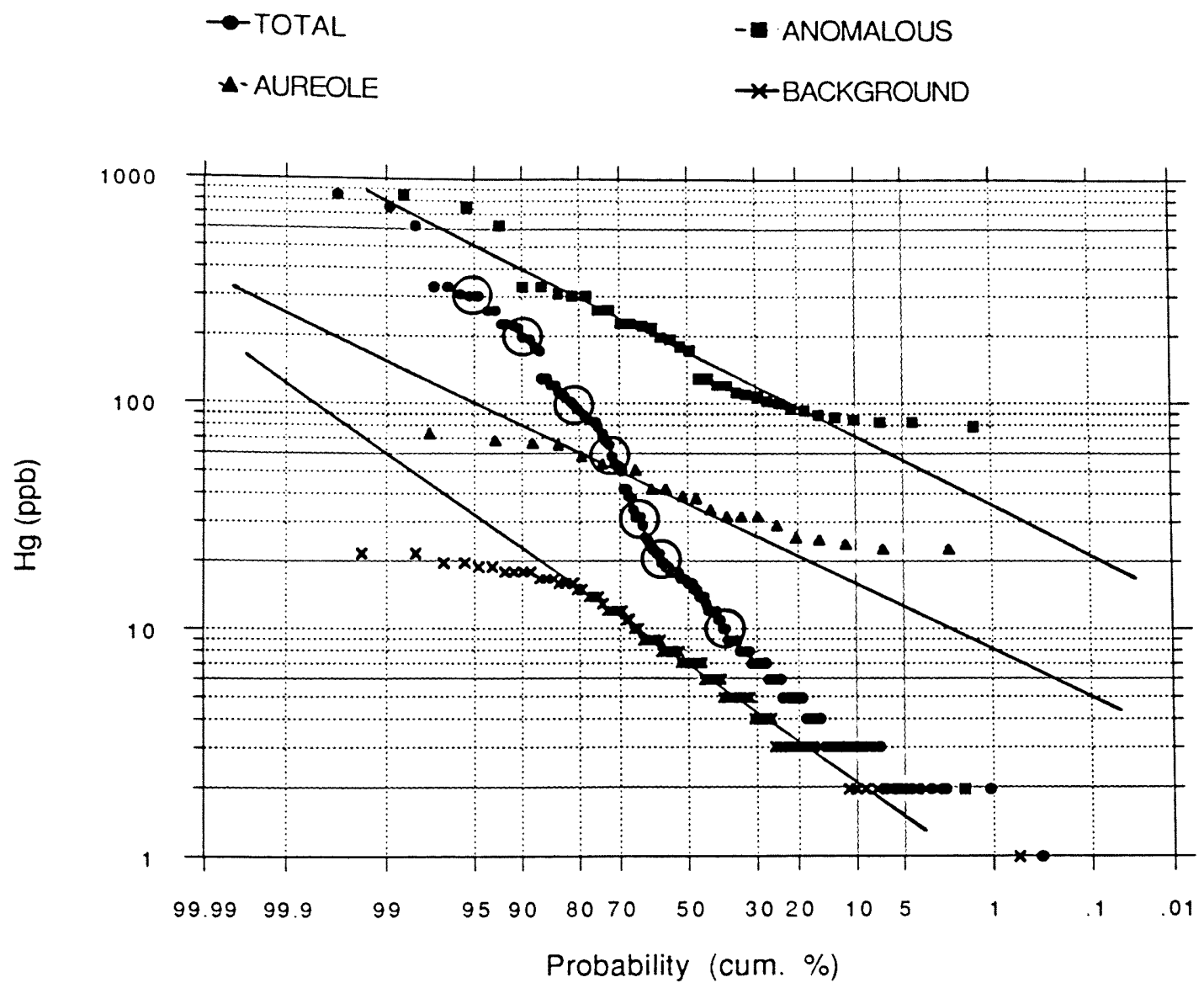

FIGURE 3.3. Log probability plot of the total data set and the three groups it was separated into in Figure 3.2. The straight lines drawn through the three populations are best fit lines and represent the three populations of the total data set. The placement of these lines was checked by the method described in the text. The "o" marks drawn on the total data points are the check points and show a good match. 


\begin{tabular}{|ccccccccc} 
POPULATIONS & PROP. $(\%)$ & \# SAMPLES & $\mathrm{b}$ & $\mathrm{b}+\mathrm{s}$ & $\mathrm{b}-\mathrm{s}$ & $\mathrm{T}$ (low) & T (high) \\
\hline Background & 59.9 & 85 & 7 & 18 & 2.7 & $\mathrm{~N} / \mathrm{A}$ & 80 \\
Aureole & 15.5 & 22 & 35 & 70 & 19 & 155 \\
Anomalous & 24.6 & 35 & 175 & 330 & 85 & 35 & $\mathrm{~N} / \mathrm{A}$ \\
Total & 100 & 142 & 17 & 130 & 3.5 & $\mathrm{~N} / \mathrm{A}$ & $\mathrm{N} / \mathrm{A}$ \\
\hline
\end{tabular}

TABLE 3.1. Probability distribution of mercury by population. $b=$ geometric mean, $s=$ standard deviation, $t=$ threshold. 


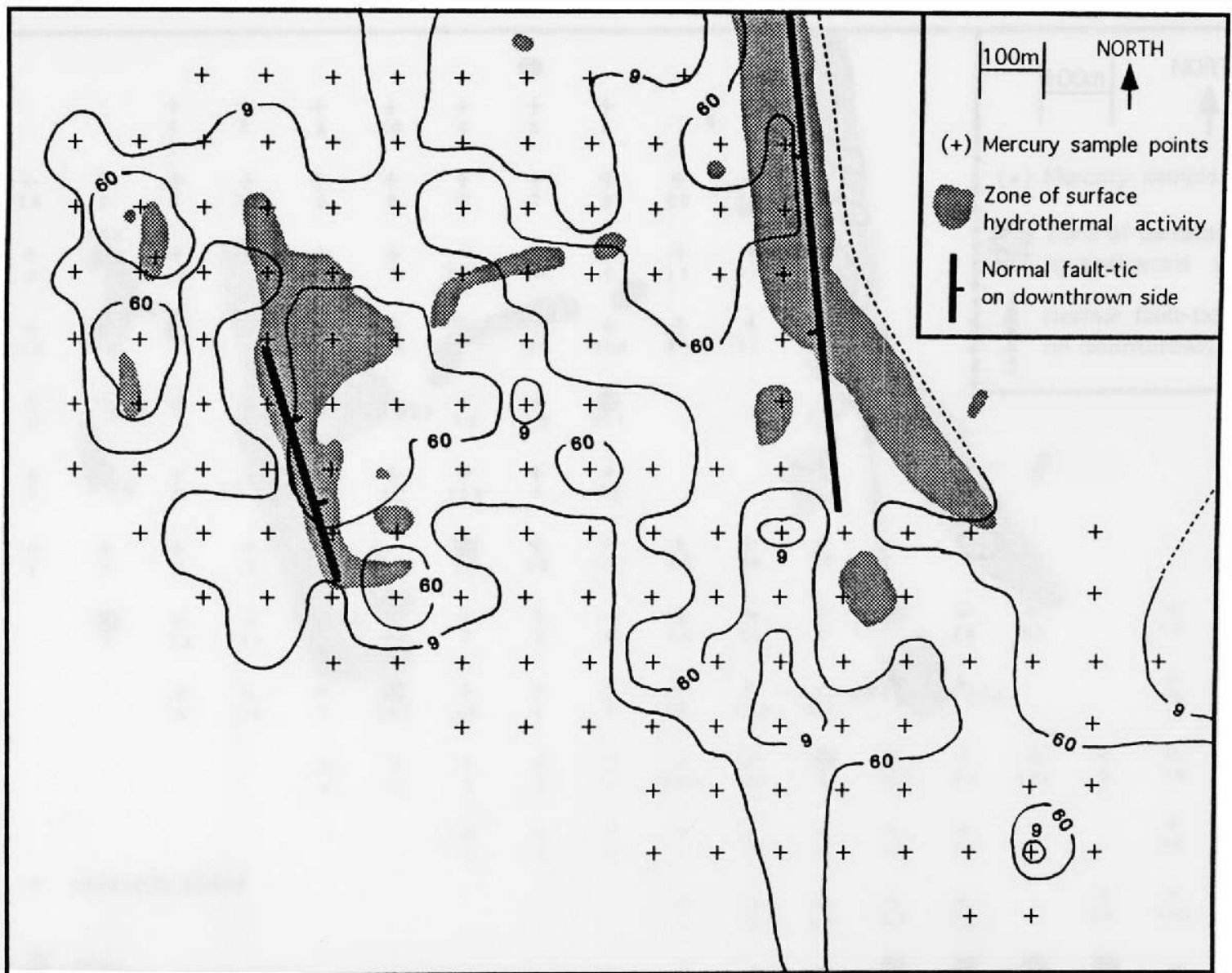

FIGURE 3.4. Contour map of mercury concentrations. Contour lines at 9 and $60 \mathrm{ppb}$ by weight were chosen for reasons described in the text. Concentrations above 60 ppb have been determined to be anomalous with extreme certainty. Concentrations from 60 to $9 \mathrm{ppb}$ are probably anomalous, but with decreasing certainty. Notice how the 9 ppb contour line. which encloses anomalous concentrations of lower certainty, wraps around the $60 \mathrm{ppb}$ contour line. This suggests that most concentrations between 9 and $60 \mathrm{ppb}$ are in fact anomalous. 


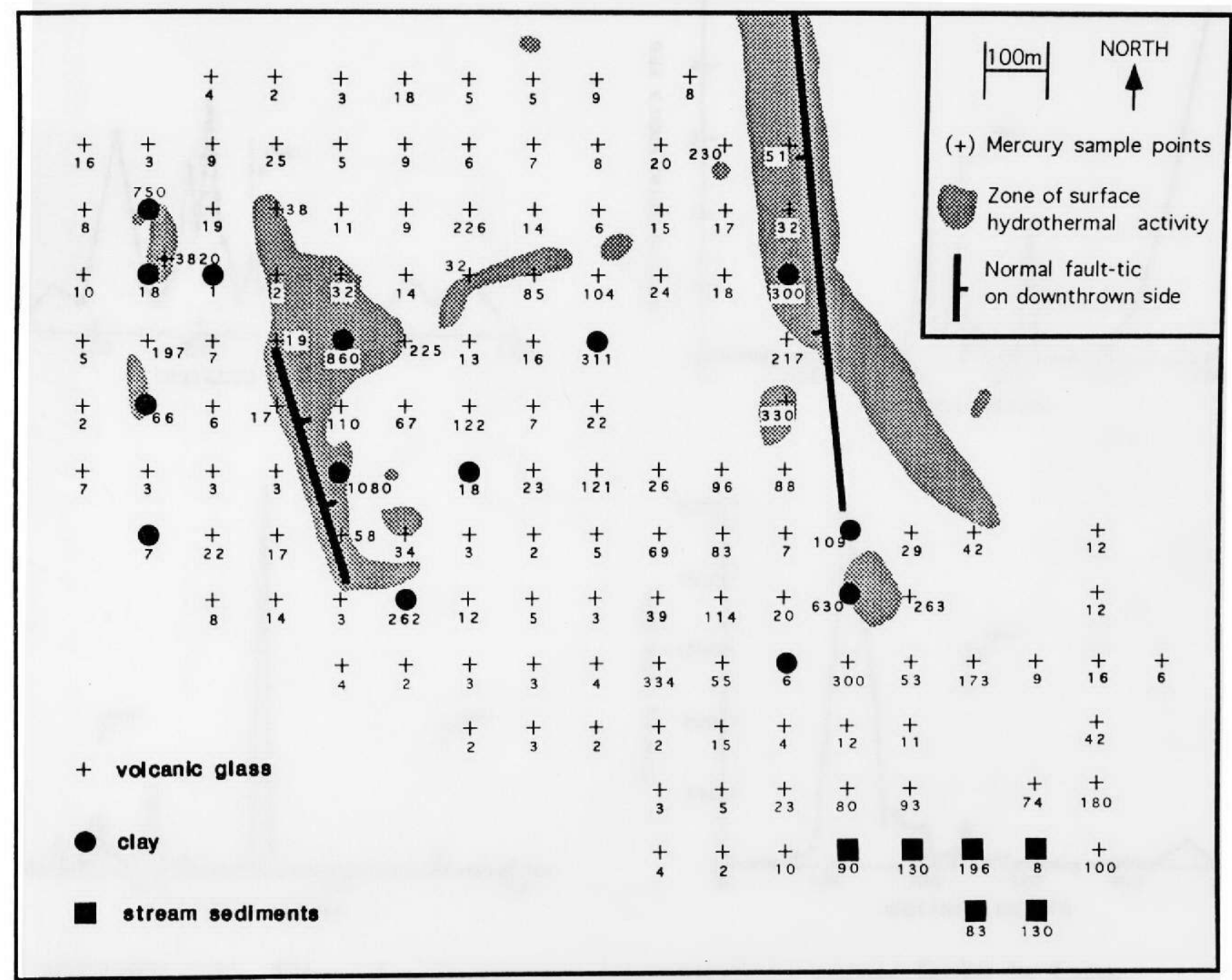

FIGURE 3.5. Distribution of soil types based on petrographic analysis of soil mercury samples plotted with soil mercury concentrations. 

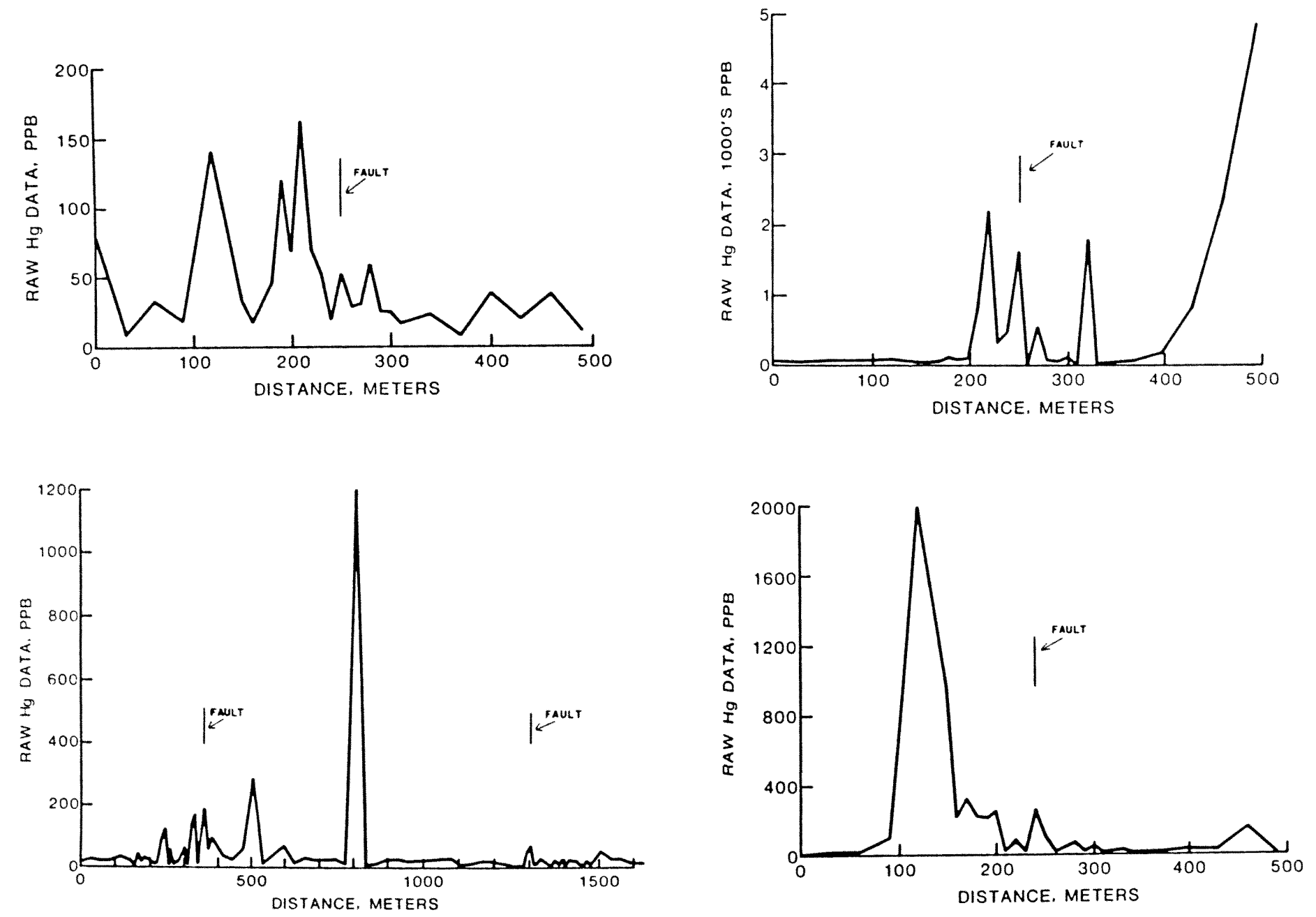

FIGURE 3.6. Plots of soil mercury concentrations across faults in Long Valley (modified from Klusman and Landress, 1979). Notice how peak concentrations usually do not occur at the fault lines. 

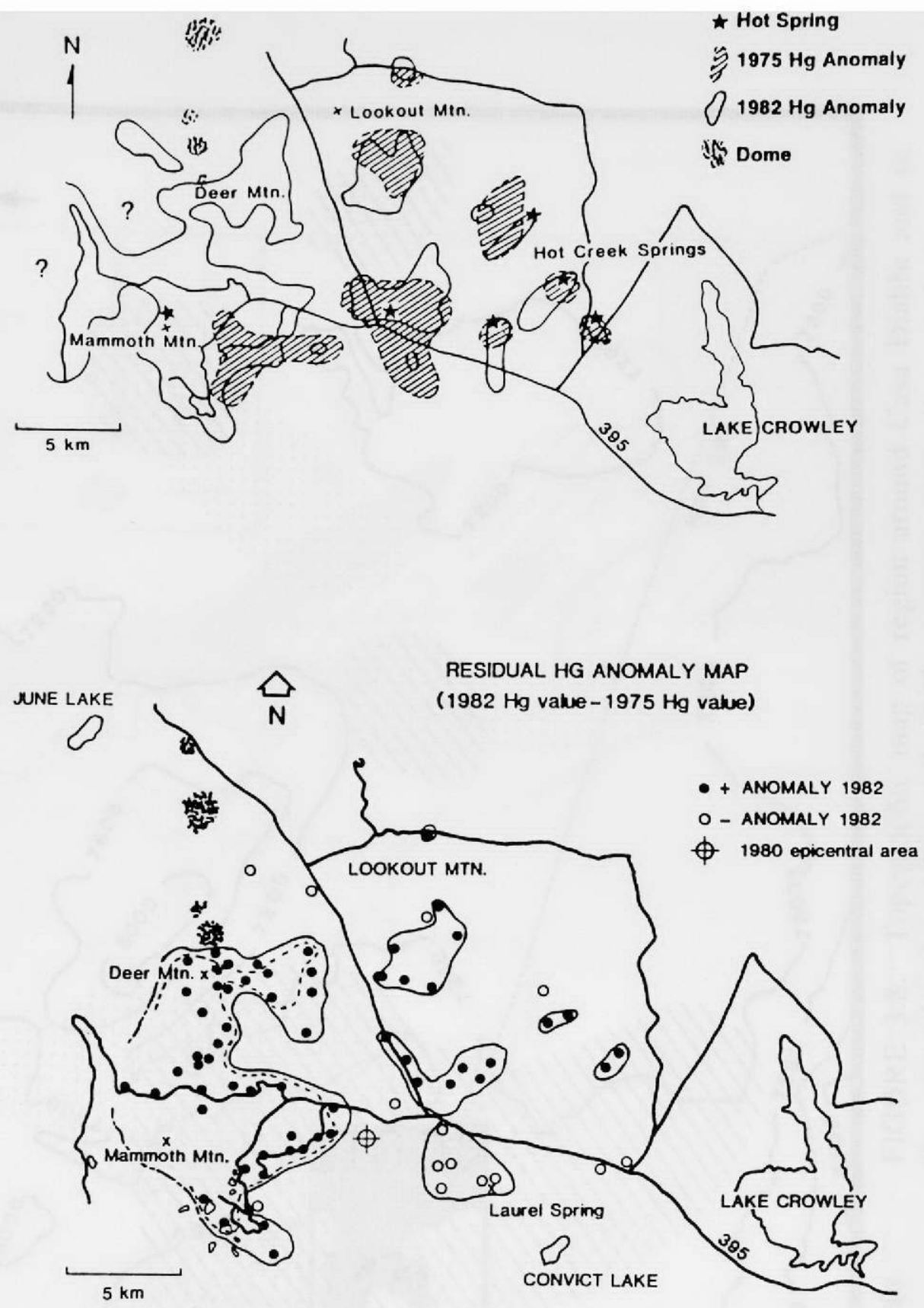

FIGURE 3.7. Above: Anomaly patterns of 1975 and 1982 surveys. Below: Residual mercury anomaly pattern (1982 values minus 1975 values). Points outside dashed contour have residual mercury values between 30 and $50 \mathrm{ppb}$; points inside dashed contour have values greater than $50 \mathrm{ppb}$ (from Varekamp and Buseck, 1984). 


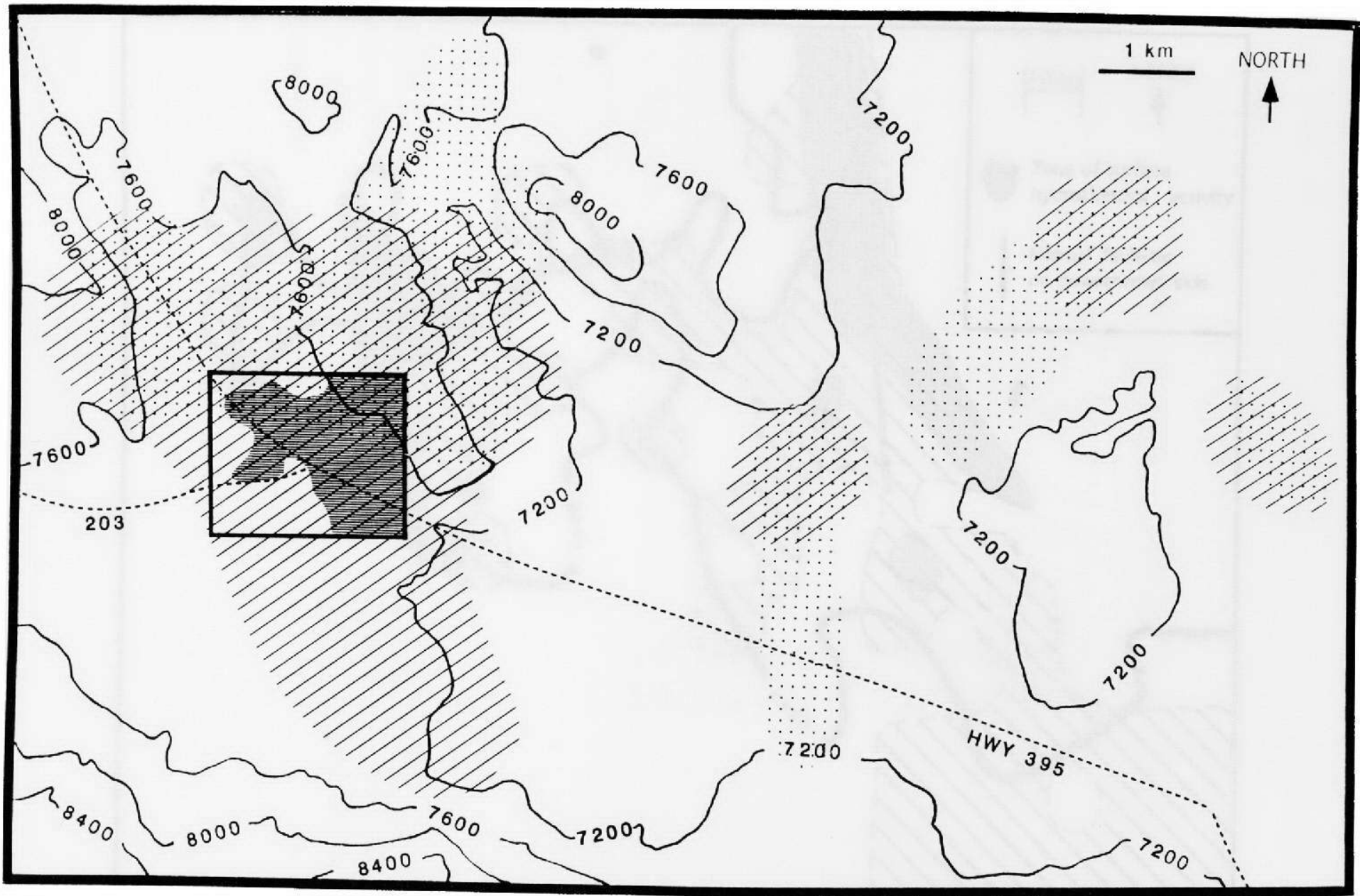

Y. $1975 \mathrm{Hg}$ Anomaly $1982 \mathrm{Hg}$ Anomaly

$1992 \mathrm{Hg}$ Anomaly
FIGURE 3.8. Topographic map of region around Catsa Diablo and to the east showing 1975 and 1982 mercury anomalies of from Varekamp and Buseck. 1984. Boxed region denotes the map area of the present study. 


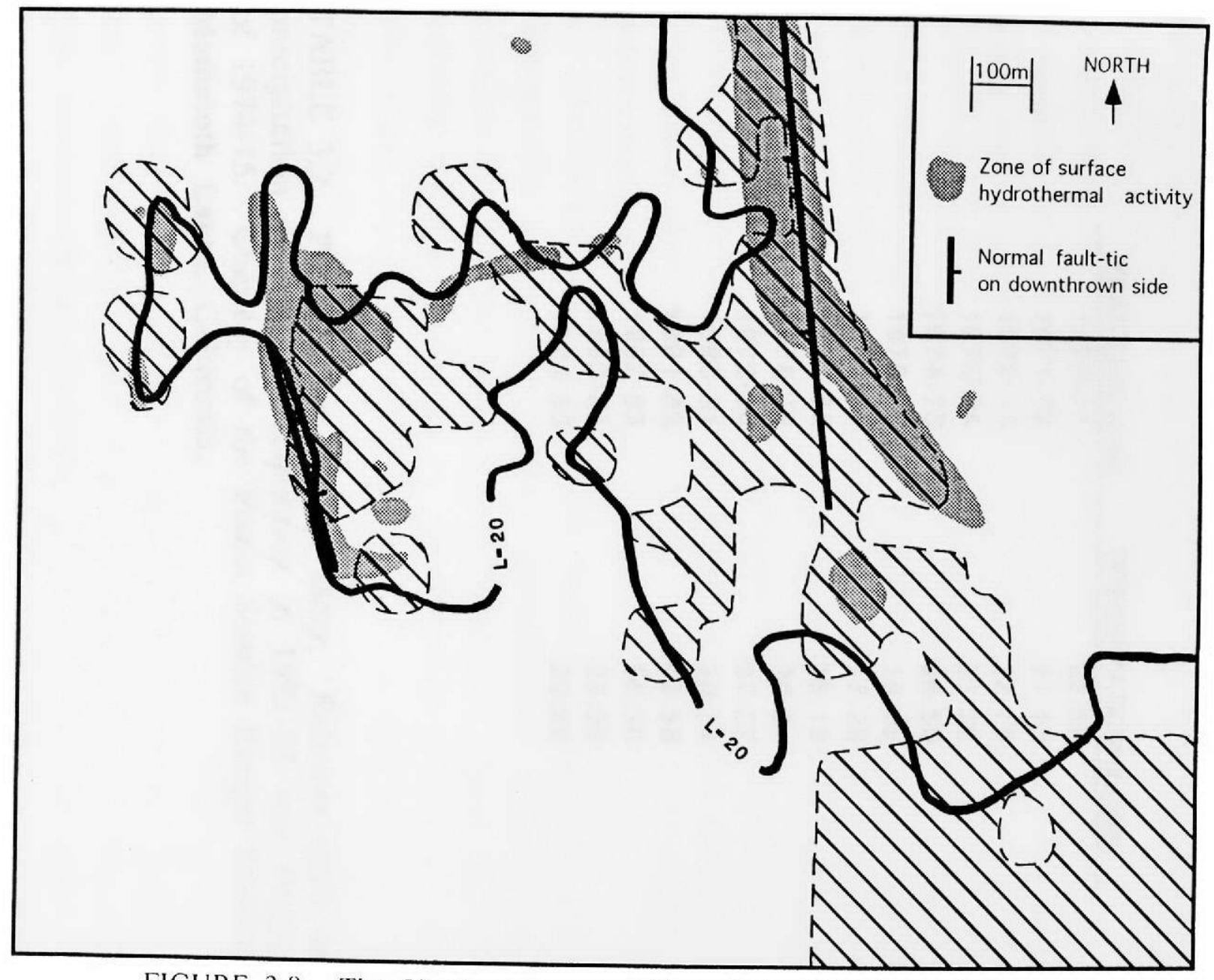

FIGURE 3.9. The $50 \mathrm{ohm}-\mathrm{m}$ contour line of the $20 \mathrm{~m} \mathrm{~L}$-spacing resistivity profile (labeled as $\mathrm{L}=20$ ) superimposed on zones of anomalous soil mercury. Enclosed areas with diagnal pattern denote soil mercury concentrations of greater or equal to $60 \mathrm{ppb}$. 


\begin{tabular}{cc} 
YEAR (July-June) & PRECIPITATION (inches) \\
\hline $1970-71$ & 22.65 \\
$1971-72$ & 21.10 \\
$1972-73$ & 32.15 \\
$1973-74$ & 31.95 \\
$1974-75$ & 26.50 \\
$1975-76$ & 19.68 \\
$1976-77$ & 17.28 \\
$1977-78$ & 36.18 \\
$1978-79$ & 30.61 \\
$1979-80$ & 37.37 \\
$1980-81$ & 20.11 \\
$1981-82$ & 42.58 \\
$1982-83$ & 55.90 \\
$1983-84$ & 29.90 \\
$1984-85$ & 22.88
\end{tabular}

TABLE 3.2. Precipitation at Lake Mary. Relavent years and precipitation in bold. Precipitation in 1981-82 was nearly twice that of 1974-75. Courtesy of the Forest Service Ranger Station at Mammoth Lakes, California. 


\section{CHAPTER 4: CONCLUSIONS}

The first conclusion is that the abundant surface hydrothermal activity at Casa Diablo is a product of location, topography, and structure. Hydrothermal water rises at a very shallow angle from an east-northeast direction and toward Casa Diablo. Because Casa Diablo is situated at a topographic low at the southern flank of the resurgent dome, the hydrothermal water comes within easy reach of the surface. But, this is not enough to generate the formation of surface hydrothermal features. Large areas at, and to the east of, Casa Diablo are within easy reach of hydrothermal water, but have not developed surface hydrothermal features. Zones of surface hydrothermal activity are closely associated with two important normal faults that cross the area. Low subsurface resistivities and mercury anomalies are also associated with the faults and surface thermal features. These data indicate the upward movement of hydrothermal fluid (both liquid and vapor) is concentrated predominantly near the faults.

The second conclusion is that there are secondary factors that influence the location of surfice hydrothermal features and mercury anomalies that are not located near the faults. Some may be controlled by the movement of hydrothermal fluid away from the faults along small, unmapped fractures or porous zones in the tuffeceous host rocks. Others maly be tapping hydrothermal fluid more directly from the source in the same manner.

Mercury anomalies not associated with surface hydrothermal features can be explained by inadequate or restricted flow. If the upward flow is too weak, a noticeable hydrothermal feature my not form. Alternatively, more abundant upward flow, which would more likely cause at surface hydrothermal feature to form, may be dispersed by permeable ground. This is unlike the concentrating of rising hydrothermal fluid that probably occurs betleath active surface zones. Clay formation and mineralization, in response to upward flowing hydrothermal fluid, causes the ground to become impermeable. This would only permit the existence of discrete 
conduits opened, for instance, by fault movement. When even a small quantity of hydrothermal fluid rises to the surface through such a conduit, its escape is easily seen.

The third and forth conclusions deal with the relationship between the hydrothermal system at Casat Diablo, with that of Long Valley. The third conclusion is based primarily on resistivity data. I interpret the strong resistivity gradient in the western section of the map area to be an indication of near surface upwelling. It is the location where the hydrothermal water from the deep reservoir beneath Long Valley, rises to the surface to feed the surface hydrothermal activity at Casa Diablo (conclusion 3). Although the angle of upward flow from the deep reservoir was shown to be very shallow, structure or strattigraphy may cause it to be more step-like in some places. This may explain the relatively steep angle of upwelling the resistivity data indicates.

The forth conclusion is that, after upwelling, the hydrothermal water flows down a topographic gradient toward the east and remains near the surface due to its buoyancy. The continuation of low, near-surface resistivities to the eastern edge of the map area supports this. Also, the southeastern mercury anomaly suggests the presence of near-surface hydrothermal fluid. The flow ultimately reaches Lake Crowley.

The final conclusion is that the joint use of resistivity profiling and soil mercury analysis is a highly effective method of probing the subsurface conditions of hydrothermal active environments. Resistivity profiles can be used as the basis for models of water dominated hydrothermal systems. The depth 10, and extent of, hydrothermally permeated ground can be determined by resistivity profiling.

Soil mercury analyses give more confidence to models derived from resistivity profiling. When the map of soil mercury anomalies is combined with the $20 \mathrm{~m}$ L-spacing map of resistivity, the correlation is clear (Figure 3.9). A even greater value of soil mercury analyses is in locatting zones of boiling. Upward flow of hydrothermal fluid is the most likely caluse of boiling. Therefore, soil mercury 
analyses give clues as to the dynamics of a hydrothermal system. This information is especially useful at locations that lack surface hydrothermal features.

\section{FURTHER WORK}

The data and ideas presented in this study permit many avenues of continuing research. These include a deeper penetrating resistivity survey to the west and northwest of this study area. Such an investigation could reveal more about the flow of hydrothermal water toward Casa Diablo. Factors like the lateral extent of the flow zone and any step-like behavior of its upward flow could be defined. A longer term study of the extent of mercury anomaties to the south of Casa Diablo compared to precipitation and/or the actual water table is another worthwhile line of research. This would help determine just how cold-hydrothermal water interactions influence the movement, extent, and boiling of the hydrothermal water. 


\section{REFERENCES}

Bailey, R. A., Dalrymple, G.B., and Lanphere, M. A., 1976, Volcanism, structure, and geochronology of Long Valley caldera, Mono County, California: Jour. Geophys. Research, 81-5: 725-744.

Connor, C.B., 1989, Anomalous soil mercury concentrations at Paricutin volcano, Michoacan - Guanajuato volcanic field, Mexico: Geofis. Int., 28-5: 1029-1041.

Farrar, C.D., Sorey, M.L., Rojstaczer, S.A., Janik, C.J., Winnett, T.L., and Clark, M.D., 1987, Hydrologic and geochemical monitoring in Long Valley caldera, Mono county, California, 1985: U.S.G.S. WaterResources Investigation Report, $87-4090$.

Farrar, C.D., Sorey, M.L., Rojstaczer, S.A., Steinemann, A.C., and Clark, M.D., 1989, Hydrologic and geochemical monitoring in Long Valley caldera, Mono county, California, 1986: U.S.G.S. Watter-Resources Investigation Report, 89-4(033.

Henley, R.W., 1985, The geothermal framework of epithermal deposits: Reviews in Economic Geology, 2: 1-24.

Hill, D. P., 1976, Structure of Long Valley caldera, California, from a seismic refraction experiment: Jour. Geophys. Research, 81-5: 745753 .

Hill, D. P., 1989, Temperatures at the batse of the seismogenic crust beneath Long Valley caldera, California, and the Phlegrean Fields caldera, Italy. Volume on Volcanic Seismology, Springer-Verlag (in press). 
Klusman, R.W. and Landress, R.A., 1979, Mercury in soils of the Long Valley, California, geothermal system: J. Volcanol. Geotherm. Res., 5: 49-65.

Lepeltier, C., 1969, A simplified statistical treatment of geochemical data by graphical representation: Economic Geology, 64: 538-550.

Nathenson, M., and Muffler, L. J. P., 1975, Geothermal resources in hydrothermal convection systems and conduction-dominated areas; in White, D E., and Williams, D. E., eds., Assessment of geothermal resources of the United States, 1975: U. S. Geol. Survey Cir., 726: 104121.

Sinclair, A.J., 1974, Selection of threshold values in geochemical data using probability graphs: J. Geochem. Explor., 3: 129-149.

Sorey, M. L., Suemnicht, G. A., Struchio, N. C. and Nordquist, G. A., 1991. New evidence on the hydrothermal system in Long Valley caldera, California, from wells, fluid sampling, electrical geophysics, and age determinations of hot-spring deposits: J. Volcanol. Geotherm. Res., 48: 229-263.

Sorey, M. L., 1985. Evolution and present state of the hydrothermal system in Long Valley caldera: J. Geophys. Res., 9()(B13): 11,21911,228 .

Varekamp, J.C. and Buseck, P.R., 1983a, Hg anomalies in soils: A geochemical exploration method for geothermal areas: Geothermics, 12: $29-47$.

Varekamp, J.C. and Buseck. P.R., 1984, Changing mercury anomalies in Long Valley, California: Indication for magma movement or seismic activity: Geology, 12: 283-286. 